\title{
Assessing the Quality of Shortwave and Longwave Irradiance Observations over the Ocean: One Year of High-Time-Resolution Measurements at the Lampedusa Oceanographic Observatory
}

\author{
Alcide di SARra, ${ }^{\mathrm{a}}$ CARlo Bommarito, ${ }^{\mathrm{b}}$ FABrizio Anello, ${ }^{\mathrm{b}}$ TATIANA Di IORIO, ${ }^{\mathrm{a}}$ \\ Daniela Meloni, ${ }^{\mathrm{a}}$ Francesco Monteleone, ${ }^{\mathrm{b}}$ Giandomenico PaCe, ${ }^{\mathrm{a}}$ SAlvatore Piacentino, ${ }^{\mathrm{b}}$ \\ AND DAMIANO SFERLAZZO ${ }^{c}$ \\ ${ }^{a}$ Laboratory for Observations and Analyses of Earth and Climate, National Agency for New Technologies, \\ Energy, and Sustainable Economic Development (ENEA), Rome, Italy \\ ${ }^{\mathrm{b}}$ Laboratory for Observations and Analyses of Earth and Climate, National Agency for New Technologies, \\ Energy, and Sustainable Economic Development (ENEA), Palermo, Italy \\ ${ }^{\mathrm{c}}$ Laboratory for Observations and Analyses of Earth and Climate, National Agency for New Technologies, \\ Energy, and Sustainable Economic Development (ENEA), Lampedusa, Italy
}

(Manuscript received 6 February 2019, in final form 8 June 2019)

\begin{abstract}
Measurements of downwelling shortwave (SW) and longwave (LW) irradiance were carried out on an oceanographic buoy close to the island of Lampedusa (Italy), in the central Mediterranean Sea. Irradiance measurements on the buoy were acquired at high time resolution together with the radiometer pitch and roll angles. The measurements carried out during 2016 have been compared with ground-based observations made at the Lampedusa Atmospheric Observatory, about $15 \mathrm{~km}$ northeast of the buoy. The radiometers were compared before and after deployment on the buoy and are traceable to the World Radiometric Reference scale. The SW measurements were corrected for the thermal offset. A small bias (measurements over the sea are smaller than on land) of about $-2 \mathrm{~W} \mathrm{~m}^{-2}$ is found in the daily mean $\mathrm{SW}$, and a moderate bias of $+6.2 \mathrm{~W} \mathrm{~m}^{-2}$ (irradiance over the sea is larger than on land) is found in the LW. Similar biases are found when instantaneous measurements obtained with horizontal radiometers, clean domes, and cloud-free conditions are selected, suggesting that impacts of the moving platform and poor dome cleaning are minor at this site. The effect of the mean tilt angle was also investigated. Deviations in the hourly mean SW irradiance are on the order of $20 \%$ for a mean offset of $4^{\circ}$ with respect to the solar zenith angle; the effect of tilt angle on LW irradiance appears to be negligible. Radiative transfer calculations show that the observed biases may be ascribed to the differences in the instrument altitude (through radiation absorption, scattering, and emission by the atmospheric constituents in the lowest atmospheric layers) and in the SW surface albedo.
\end{abstract}

\section{Introduction}

Measuring components of the surface energy budget over the ocean is crucial to understanding climate at the regional and global scale (e.g., Ghate et al. 2009). The radiative quantity relevant for the surface energy budget is the irradiance, which is the radiant power reaching a horizontal surface of unit area and is measured in units of watts per meter squared. The irradiance can also be calculated as the integral over a hemisphere of the radiance weighted for the cosine of the incidence angle, which is the angle between the incoming radiation direction and the normal to the surface. The downwelling

Corresponding author: Alcide di Sarra, alcide.disarra@enea.it irradiance in some cases is also called downwelling radiation.

In the Mediterranean Sea, components of the surface ocean energy budget have been used to investigate the regional climate (Matsoukas et al. 2005; Nabat et al. 2015) and to close the basinwide heat budget and estimate the contribution of evaporation to sea level changes (e.g., Gilman and Garrett 1994; Dubois et al. 2012). These analyses show that large differences exist among various estimates of the radiative components of the surface energy budget (e.g., Pettenuzzo et al. 2010; Dubois et al. 2012). Several studies have emphasized that atmospheric aerosol may play a large role, in addition to clouds, in modulating the shortwave (SW) irradiance (Gilman and Garrett 1994; Tragou and 
Lascaratos 2003; di Sarra et al. 2008) and may contribute to the observed differences.

Measurements of radiation components over the open ocean are sparse. In addition, intrinsic difficulties are associated with measurements over buoys or ships. Instruments on buoys, in particular, are run unattended for extended time intervals, and a reduction of accuracy is expected in particular as a result of changes of the radiometer attitude (e.g., MacWhorter and Weller 1991) and poor dome cleaning (Waliser et al. 1999; Foltz et al. 2013). Some studies have investigated the influence of the tilt angle on SW irradiance measurements (e.g., Katsaros and DeVault 1986; Long et al. 2010; Medovaya et al. 2002; Canepa et al. 2015). These studies suggest that, while errors on time averages due to buoy rocking tend to be small, mean tilts may produce significant effects. Waliser et al. (1999) estimated that a mean buoy tilt of $1^{\circ}$ produces a $2 \%-3 \% \mathrm{SW}$ irradiance bias in clear-sky conditions. To our knowledge, no specific studies address this problem for the longwave (LW) irradiance component. Conversely, the role of solar radiation leakage and differential heating of the pyrgeometer dome have been studied (Pascal and Josey 2000; Meloni et al. 2012). The solar radiation leakage has been suggested as the cause for a bias in LW irradiance measurements over buoys (e.g., Yamada and Hayasaka 2016).

Waliser et al. (1999) addressed the effect of dome cleaning in the North Atlantic Ocean during the Subduction Experiment and Atlantic Stratocumulus Transition Experiment (ASTEX) in 1991-93. They recalibrated the $\mathrm{SW}$ radiometers after substitution on the buoys before and after cleaning, and found differences smaller than $2 \%$.

Measurements made west of tropical Africa, in a region characterized by intense desert dust transport and deposition, have shown a negative bias in SW irradiance with respect to satellite analyses and model calculations (e.g., Foltz et al. 2013). A 14\% decrease resulting from dust deposition on the sensor dome was measured by comparing a freshly calibrated sensor with a dirty one. Foltz et al. (2013) developed a correction scheme to take into account the effect of dust deposition on the measured SW irradiance. The produced bias does not change linearly with time, due to the effect of rain, which may add or remove dust on the dome, and to periodic instrument replacement.

The assessment of the quality of radiation measurements over buoys thus is a difficult task, also due to limitations in monitoring the instrument status and lack of reliable collocated measurements. In some cases, satellite-derived or modeled SW irradiances have been compared with measurements made on land and ocean as an indirect verification of the observation's quality on the open ocean (Gautier 1988; Bishop et al. 1997; Pinker et al. 2009; Foltz et al. 2013; Yamada and Hayasaka 2016). Radiative models have been used by several authors to assess the quality of oceanic observations (Bréon et al. 1991; Waliser et al. 1999; Medovaya et al. 2002).

Gautier (1988) compared satellite-derived SW irradiances with measurements made in 1984-85 on ship, buoy, and a small island in the central Pacific Ocean. Her analysis suggests that local effects significantly affected measurements on the selected island, and that these measurements were not representative of open-ocean conditions. Similar conclusions, with orographic effects affecting measurements at many island stations, were drawn by Bishop et al. (1997).

Few direct comparisons between measurements on buoys and independent measurements of SW and LW irradiances have been carried out (e.g., Weller and Anderson 1996; Burns et al. 2000; Cronin et al. 2006). These comparisons, however, cover limited time intervals and, consequently, a subset of possible environmental conditions.

Weller and Anderson (1996) compared measurements made on ships and buoys in three different periods of 1992 and 1993 in western equatorial Pacific. They found a very good agreement between measurements of LW irradiances, while SW irradiances differed up to $30 \mathrm{~W} \mathrm{~m}^{-2}$.

Burns et al. (2000) compared measurements on aircraft, on ship and on buoy during the Tropical Ocean and Global Atmosphere Coupled Ocean-Atmosphere Response Experiment (TOGA COARE) in 1992-93. The mean SW irradiance difference between ship and aircraft measurements was $-8 \pm 34 \mathrm{~W} \mathrm{~m}^{-2}$, and that between buoys and aircraft measurements was $+8 \pm$ $41 \mathrm{~W} \mathrm{~m}^{-2}$. For the LW, the mean ship-aircraft difference between LW irradiance measurements on ship and aircraft was $-3 \pm 5 \mathrm{~W} \mathrm{~m}^{-2}$, whereas that between buoys and aircraft observations was $-4 \pm 7 \mathrm{~W} \mathrm{~m}^{-2}$.

Cronin et al. (2006) analyzed collocated measurements from ships and buoys made within about $10 \mathrm{~km}$ distance, covering 17 days in the period 2000-03 at the Tropical Atmosphere Ocean (TAO) moorings. The buoy-ship mean difference was $-4 \mathrm{~W} \mathrm{~m}^{-2}$ for 6-h averages and $-11 \mathrm{Wm}^{-2}$ for daily averages. Mean difference for $\mathrm{LW}$ was $-1 \mathrm{Wm}^{-2}$ for daily averages and $-4 \mathrm{~W} \mathrm{~m}^{-2}$ for 6-h averages. The root mean difference between ship and buoy was $26 \mathrm{~W} \mathrm{~m}^{-2}$ for SW, and about $6 \mathrm{~W} \mathrm{~m}^{-2}$ for $\mathrm{LW}$ observations. It must be pointed out that this study, although it covered a limited time interval, found that the differences between ship and 
buoy longwave irradiance measurements were well within $\pm 1 \%$. Waliser et al. (1999) compared SW irradiance observations on a buoy with two ship-based climatologies, finding significant differences (around 4\% and $20 \%$, respectively).

It must be emphasized that these differences may also depend on instrument type, characteristics, and calibration frequency and strategy. All of the previous studies were based on measurements of SW irradiance made with Eppley 8-48 and Precision Spectral Pyranometers and measurements of LW irradiance made with Eppley Precision Infrared Radiometers.

In this study the quality of open-ocean measurements on a buoy is investigated by comparing observations made on a buoy and on a small Mediterranean island. The two sites are within a distance of $15 \mathrm{~km}$. The island is small and flat, and very limited local effects are expected on the cloud distributions and downwelling irradiance. High-time-resolution measurements are made at both sites. In particular, measurements of radiometer signals and attitude have been carried out on the buoy at $1-\mathrm{Hz}$ repetition rate with the aim of investigating the effect of attitude changes. The same type of radiometers (Kipp and Zonen CMP21 pyranometers for SW irradiance and Kipp and Zonen CGR4 pyrgeometers for LW irradiance) are used on land and on the sea. They have been calibrated on the same reference scale, and have been compared before and after deployment on the buoy. The comparison covers a full year. The selected instruments possibly minimize effects due to cosine response in the SW, and SW leakage and differential dome heating in the LW. Thus, we believe that this comparison of SW and LW irradiances provides an insight on the capability of performing high quality irradiance measurements over the sea.

This assessment supports the use of accurate buoy data for the investigation of the heat and radiation budget in the central Mediterranean. In addition, this study opens the possibility to quantify and correct the bias introduced by carrying out measurements on the island of Lampedusa to infer the long-term behavior of solar and infrared irradiance over the central Mediterranean.

Section 2 describes the sites, instruments, and measurement strategy. Section 3 is dedicated to discussing and comparing the time series of SW and LW measurements, taking into account the effects of tilt angle and dome cleaning. A radiative transfer model analysis aimed at assessing the source of the buoyland differences has been carried out and is discussed in section 4 . Section 5 contains the main conclusions of this study.

\section{Instruments and setup}

The Lampedusa Oceanographic Observatory (OO) was deployed southwest of the island of Lampedusa, at $35.49^{\circ} \mathrm{N}, 12.47^{\circ} \mathrm{E}$, in August of 2015 . The ocean depth at the buoy site is $74 \mathrm{~m}$. The buoy was designed to minimize oscillations and rotations to allow reliable measurements of the surface heat budget. A large float placed between 8 and $13 \mathrm{~m}$ below sea level produces a strong upthrust that maintains the buoy in an almost vertical orientation and limits oscillations. Two nontwisting cables keep the body of the buoy connected to the anchor, placed on the bottom, and limit rotation. The emerged section of the buoy, shown in Fig. 1, is constituted by an 8-m-long tubing and a turret, whose base is placed about $6.5 \mathrm{~m}$ above sea level. The turret base was at about $4.5 \mathrm{~m}$ before 11 June 2016, when a 2-m extension was added to the buoy structure. Solar panels are placed east, south, and west of the turret, where power supply circuitry, data acquisition and transmission systems, and instruments for atmospheric measurements are placed.

Starting from its deployment, various instruments have been installed on the buoy. The present set includes meteorological sensors, a sonic anemometer, and radiometers in the atmospheric section; temperature/pressure sensors at various depths, a conductivity-temperaturedepth (CTD) sensor, narrowband radiometers for downwelling and upwelling radiation at two depths, and a sensor for chlorophyll, chromophoric dissolved organic matter (CDOM), and backscatter at about 5-m depth. The Lampedusa OO was developed within the RITMARE Italian flagship project (http://www.ritmare.it/en) and contributes to the Italian Fixed-Point Observatory Network (IFON) for marine environmental monitoring (Ravaioli et al. 2016). Broadband radiometers to measure the downwelling SW and LW irradiance were installed in December 2015, together with a two-axis inclinometer that provides information on the radiometer attitude in two perpendicular axes, approximately corresponding to north-south and west-east. Information on the orientation of the buoy has not been acquired until now, and the tilt angles rotate with the buoy structure. Rotation of the buoy is limited (nominally, $<5^{\circ}$ for sea state $<4$ ). The installation of a compass is planned.

The two radiometers are placed on a single plate on an arm that extends south with respect to the buoy turret. The radiometers were at about $5.8 \mathrm{~m}$ above mean sea level before 11 June 2016 and at $7.8 \mathrm{~m}$ above sea level afterward. In April 2017 the plate with the radiometers was moved farther south (from 0.5 to about $1.5 \mathrm{~m}$ from the turret) to the position shown in Fig. 1. The shortwave 


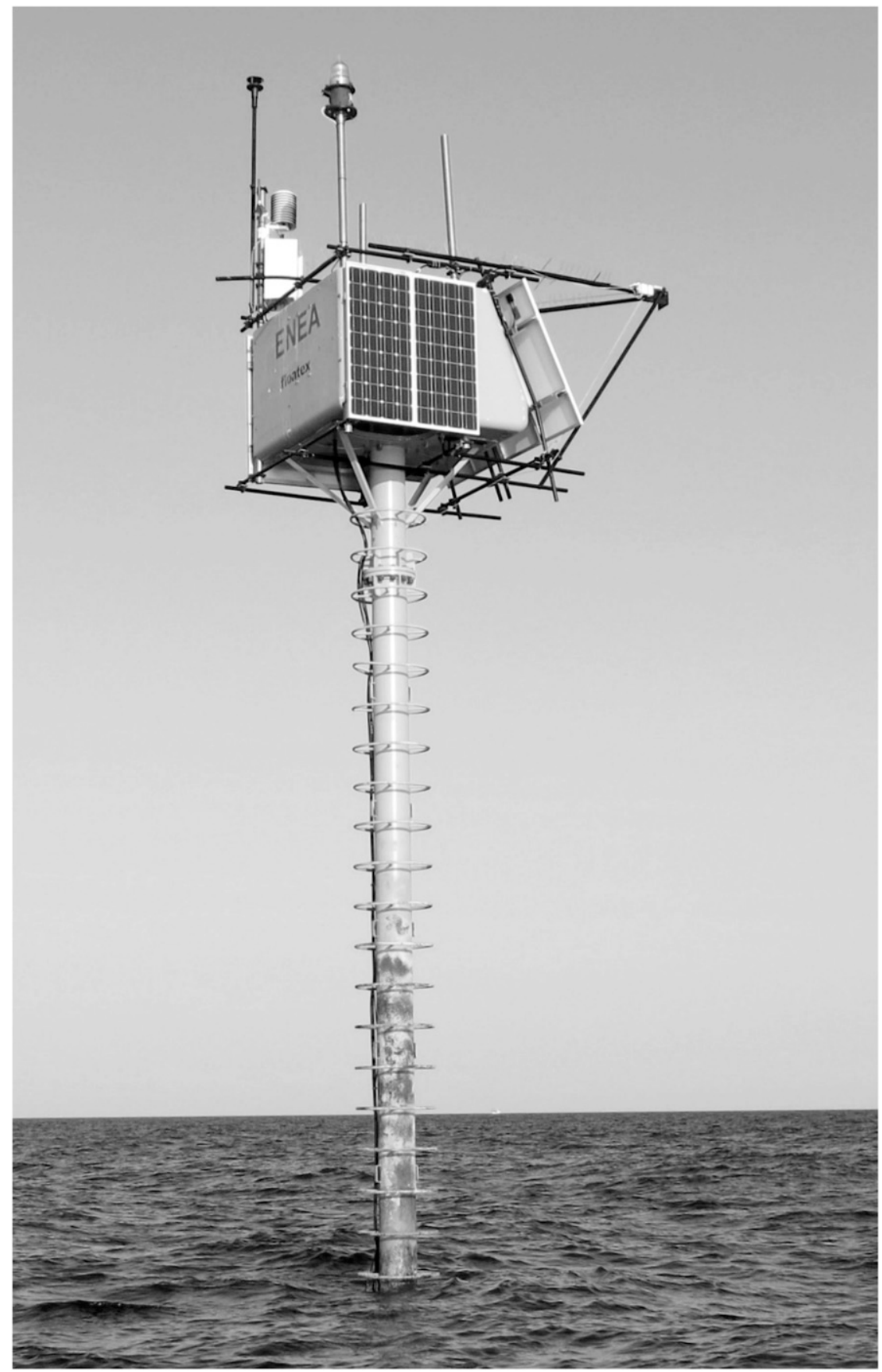

FIG. 1. View of the emerged section of the Lampedusa Oceanographic Observatory. The downwelling radiometers are placed at the end of the arm that extends southward. They were closer to the turret before April 2017.

radiometer is a Kipp and Zonen CMP21, and the longwave radiometer is a Kipp and Zonen CGR4. They are not ventilated. They have been kept in operation on the buoy throughout the period of December 2015-April 2017. In April 2017 they were replaced with a new pair that was recalibrated before deployment.
The CMP21 pyranometer was chosen because of the good cosine response (deviation $<1 \%$ up to $60^{\circ}$ solar zenith angle, and generally $<2 \%$ up to $70^{\circ}$ solar zenith angle) and the possibility to acquire the instrument temperature. The cosine response of the Eppley Precision Spectral Pyranometer, which has been used on 


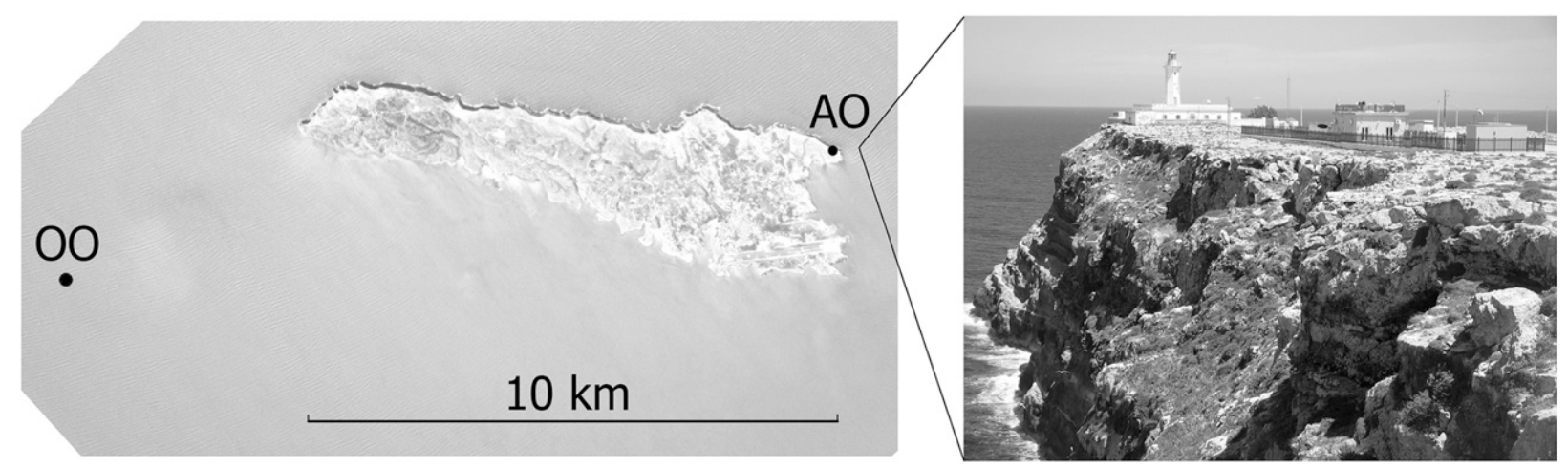

FIG. 2. (left) Image of Lampedusa taken from the International Space Station (picture ISS 024-E-10246; see acknowledgments), with the positions of $\mathrm{OO}$ and $\mathrm{AO}$ indicated. (right) View of the Atmospheric Observatory, as seen approximately from west.

various buoys (Servain et al. 1998; Waliser et al. 1999; Burns et al. 2000; Cronin et al. 2006; Weller et al. 2012; Canepa et al. 2015), is expected to be of somewhat lower quality (Michalsky et al. 1995) than that for CMP21.

Eppley Precision Infrared Radiometers (PIR) have been mostly used on buoys (e.g., Burns et al. 2000; Cronin et al. 2006; Canepa et al. 2015). We have used the CGR4 because it displays a smaller solar radiation leakage than PIR (Meloni et al. 2012), and possibly a smaller effect from inhomogeneous dome temperature (Philipona et al. 2001). These properties may be particularly relevant when radiometers are not ventilated and shaded, as it is the case at OO.

Several solar panels were lost and the pole supporting the radiometer plate was bent during a strong storm that occurred on 16-17 January 2016. The radiometers were repositioned in horizontal position on 19 February 2016.

In this study, data from the buoy broadband radiometers and their attitude acquired during the first year of observation, essentially 2016, are used together with measurements made at the Lampedusa Atmospheric Observatory $\left(\mathrm{AO} ; 35.52^{\circ} \mathrm{N}, 12.63^{\circ} \mathrm{E}\right)$. The $\mathrm{AO}$ was set up in 1997 on a promontory on the northeastern coast of Lampedusa. Figure 2 shows a map with the position of $\mathrm{AO}$ and $\mathrm{OO}$, with a picture of AO. A variety of atmospheric observations have been progressively added at AO. These include measurements of meteorological parameters, ultraviolet, solar, and infrared radiation, aerosol properties, clouds, ozone, greenhouse gases, and so on (http://www.lampedusa.enea.it; Ciardini et al. 2016). Lampedusa contributes to the World Meteorological Organization Global Atmosphere Watch network, the Integrated Carbon Observation System, the Aerosol Robotic Network, and other measurement networks.

Shortwave and longwave irradiance observations, in particular, have been used in a number of studies to investigate relationships linking radiation and atmospheric aerosols (e.g., Casasanta et al. 2011; di Sarra et al. 2011; Meloni et al. 2005, 2015, 2018), clouds (Mateos et al. 2011), and atmospheric chemical composition (e.g., Mailler et al. 2016). The SW and LW radiometers operational at AO in the period of this study were Kipp and Zonen CMP21 and CGR4, respectively. They are installed on the roof of the AO main building, at about $50 \mathrm{~m}$ above mean sea level. They are regularly cleaned, and they are ventilated. The CGR4 is mounted on a solar tracker, and direct solar radiation is shaded. The pyranometer calibration is routinely referenced to the World Radiation Reference (WRR) solar irradiance scale (WMO 2014) approximately once per year, and the pyrgeometer calibration is referenced to the World Infrared Standard Group (WISG; WMO 2014) every 12-15 months.

The radiometers installed on the buoy were run on the roof of $\mathrm{AO}$, in parallel with those routinely operated at the site, before and after deployment on the buoy. Table 1 reports the serial numbers of CMP21 and CGR4 radiometers operating at $\mathrm{AO}$ and $\mathrm{OO}$ and dates of the intercomparisons.

In this study we use the measurements made at AO, which are routinely cleaned and checked, as reference for a comparison with those made at OO. The distance between $\mathrm{AO}$ and $\mathrm{OO}$ is about $15 \mathrm{~km}$. The observations

TABLE 1. Radiometer type, serial number (s/n), and deployment periods.

\begin{tabular}{ccc}
\hline $\begin{array}{c}\text { Instrument type } \\
\text { and s/n }\end{array}$ & \multicolumn{1}{c}{ Deployment at AO } & $\begin{array}{c}\text { Deployment } \\
\text { at OO }\end{array}$ \\
\hline CMP21 090206 & Continuous \\
CMP21 140332 & 27 Feb-17 Aug 2015 a and & 3 Dec 2015- \\
& 7 Apr-31 May 2017 & 6 Apr 2017 \\
CGR4 090107 & Continuous \\
CGR4 140024 & 2 Dec-19 Dec 2014 and & 3 Dec 2015- \\
& 7 Apr-25 Oct 2017 & 6 Apr 2017 \\
\hline
\end{tabular}

a Tracker. 
made on the buoy may be influenced by a number of factors, among which orientation and dome cleaning are believed to be relevant. Thus, the measurement made at $\mathrm{OO}$ are compared with those at $\mathrm{AO}$ to investigate the role of dome cleaning, radiometer attitude, and differences in altitude and albedo.

The radiometer signals (the thermopile voltage and the case thermistor resistance for both CMP21 and CGR4) are acquired with dataloggers. The thermopile voltages are acquired as differential voltage signals by the datalogger; the signal polarization is reversed during the measurement, and possible disturbances at $50 \mathrm{~Hz}$ are filtered out to improve the measurement accuracy.

Measurements are acquired every $30 \mathrm{~s}$ at $\mathrm{AO}$, and every $1 \mathrm{~s}$, together with the radiometer attitude, at OO. The high acquisition frequency was set up to investigate the effects of the platform motion. The nominal time constant ( $63 \%$ of final value) of CMP21 is $<1.7 \mathrm{~s}$, and that of CGR 4 is $<6 \mathrm{~s}$. Thus, at least on the CMP21 data, we expect to be able to detect effects produced by the buoy oscillations.

Raw voltage signals and thermistor resistance values from CMP21 and CGR4 are stored. The thermistor resistance is converted into temperature following the Steinhart and Hart equation. The downwelling LW irradiance is obtained from the measurements of the thermopile voltage $V$ and case temperature $T$ using the following version of the expression by Philipona et al. (1995):

$$
I_{\mathrm{LW} \downarrow}=V / C(T)\left(1+k_{1} \sigma T^{3}\right)+k_{2} \sigma T^{4},
$$

where $C(T)$ is the instrument sensitivity in $V$ per watts per meter squared corrected for its dependency on temperature, $\sigma$ is the Stefan-Boltzmann constant, and $k_{1}$ and $k_{2}$ are constant values determined together with $C$ during the calibration transfer procedure.

The same procedure is applied to signals acquired at AO and OO. Estimated 2-sigma (std dev) uncertainties on CGR4 measurements are within $\pm 5 \mathrm{~W} \mathrm{~m}^{-2}$ (Meloni et al. 2018); nighttime differences between collocated pyrgeometers are always within $\pm 2 \mathrm{~W} \mathrm{~m}^{-2}$, which is the threshold defined by Philipona et al. (2001) for wellcalibrated instruments.

The downward shortwave irradiance is obtained from the acquired thermopile voltage signal and thermistor resistance. The instrument sensitivity is first corrected for its temperature dependence. The SW downward irradiance is obtained by dividing the thermopile voltage by the temperature corrected instrumental sensitivity, and by subtracting the instrumental thermal effect. This is calculated from the pyrgeometer voltage and the instrument temperature as described by Di Biagio et al. (2009). The cosine response error, as determined by the manufacturer, is $<0.7 \%$ at $60^{\circ}$ and $<1.2 \%$ at $70^{\circ}$ for CMP21 190206 and is $<1.3 \%$ at $60^{\circ}$ and $<1.6 \%$ at $70^{\circ}$ solar zenith angle for CMP21140332. No corrections for this effect have been implemented. The 2-sigma estimated uncertainty on CMP21 measurements is $1.7 \%$. This uncertainty is calculated taking into account the uncertainty on the calibration and that on the data acquisition system.

The calibration change before and after deployment on the buoy was negligible for the CGR4 and the CMP21. The differences between irradiances from CMP21 140332 calculated using the manufacturer calibration (July 2014) and those from CMP21 090206, referenced to WRR, were about $1.5 \%$ (090206 higher than 140332) before and after deployment on the buoy. The data from CMP21 140332 were thus corrected for thermal offset and referenced to the WRR. The CGR4 data were in agreement with the most recent calibration transfer to WISG.

\section{Time series of $\mathbf{S W}$ and $\mathbf{L W}$ irradiances}

\section{a. Irradiance measurements and radiometer attitude}

Figure 3 shows the evolution of shortwave and longwave irradiances and tilt angles in the north-south and west-east directions, acquired at $1 \mathrm{~s}$ time resolution, during January 2016. As expected, the tilt angles are strongly influenced by the wind and sea conditions. The radiometer angular deviations from the horizontal position are generally within a few degrees except during very rough sea conditions, when its inclination, as well as that of the buoy, may exceed $10^{\circ}$. Conditions were exceptionally rough during the 16-17 January storm, with buoy oscillations exceeding $\pm 25^{\circ}$. As discussed in the previous section, during this event the four solar panels facing south were pulled out and the arm supporting the radiometer plate was bent. As a result, the radiometer plate was tilted by approximately $8^{\circ}$ along the north-south direction (the southern side higher than the northern side of the plate) while a smaller change of about $2^{\circ}$ occurred along the east-west axis.

In January cloudy conditions are generally associated with LW irradiance larger than $350 \mathrm{~W} \mathrm{~m}^{-2}$ and a fast variability of the SW component. As discussed previously, part of the variability of SW and LW irradiance is associated with the buoy motion, while deposition of dirt on the radiometer domes may also play a role. The SW irradiance measured at noon in cloud-free conditions on 27-29 January appears significantly lower than on 9 and 11-13 January, also characterized by cloud-free 

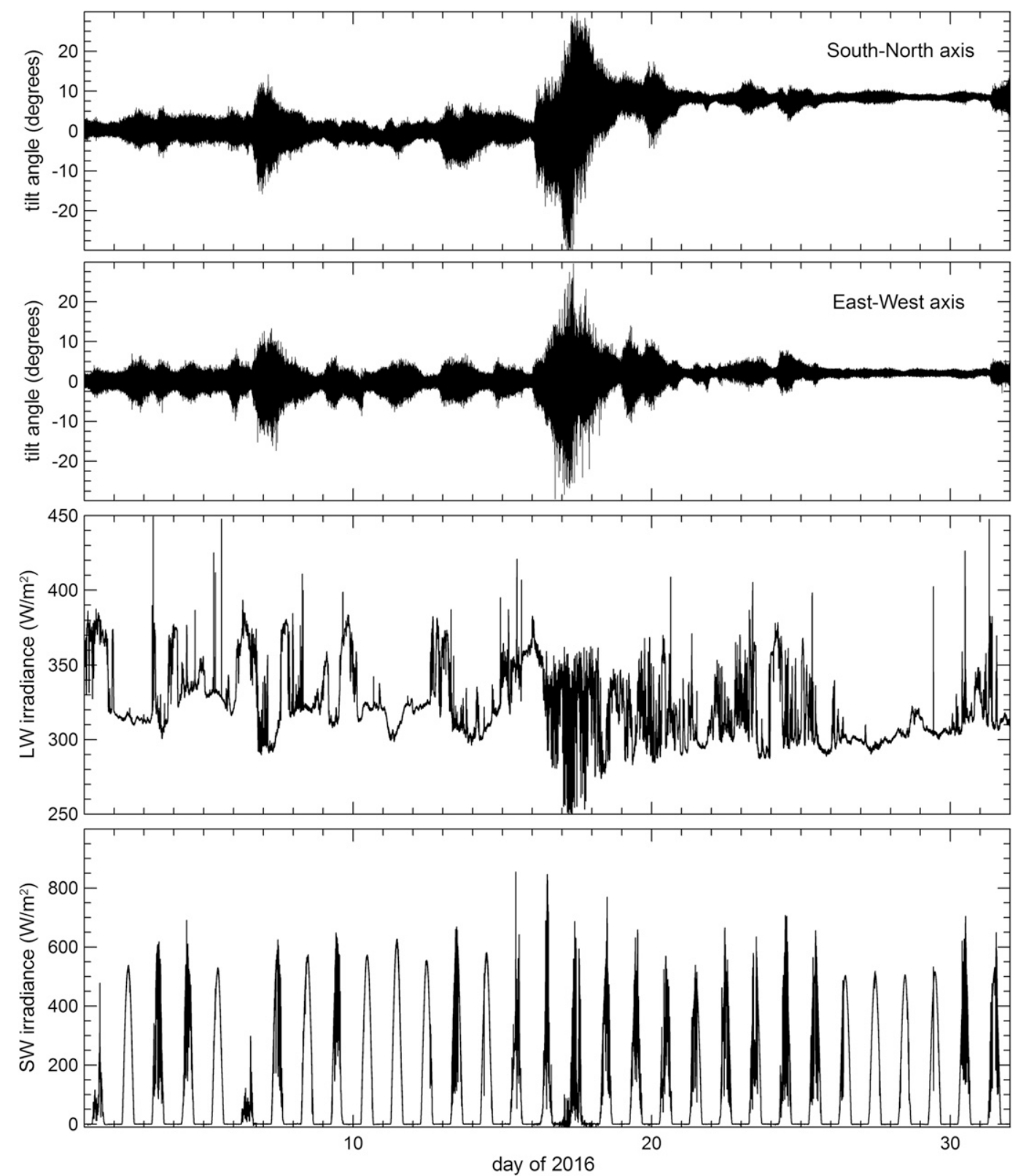

FIG. 3. Evolution of buoy and radiometer tilt axis in the (top) and north-south and (top middle) west-east directions, (bottom middle) LW irradiance measured by the CGR4, and (bottom) SW irradiance measured by the CMP21 radiometer during January 2016.

conditions. This may be seen as a combination of different atmospheric conditions and the change in pyranometer orientation after the storm; the latter effect is believed to be dominant in this case.

The evolution of the same parameters of Fig. 3 is shown in Fig. 4 for July 2016. Because of more favorable weather and sea conditions, the radiometer attitude remains stable over extended periods of time, which are characterized by very small oscillations of the buoy. As expected, cloud-free periods are much more frequent than in January.

Figure 5 shows the frequency of occurrence of the radiometer tilt angles along the two axes for January 2016, based on the inclinometer data acquired at 1-s time resolution. Two modes for the tilt angles correspond to the plate mean orientation before and after the 16-17 January storm. The most frequent radiometer position was very close to horizontal before the storm $\left(-0.20^{\circ}\right.$ along the 

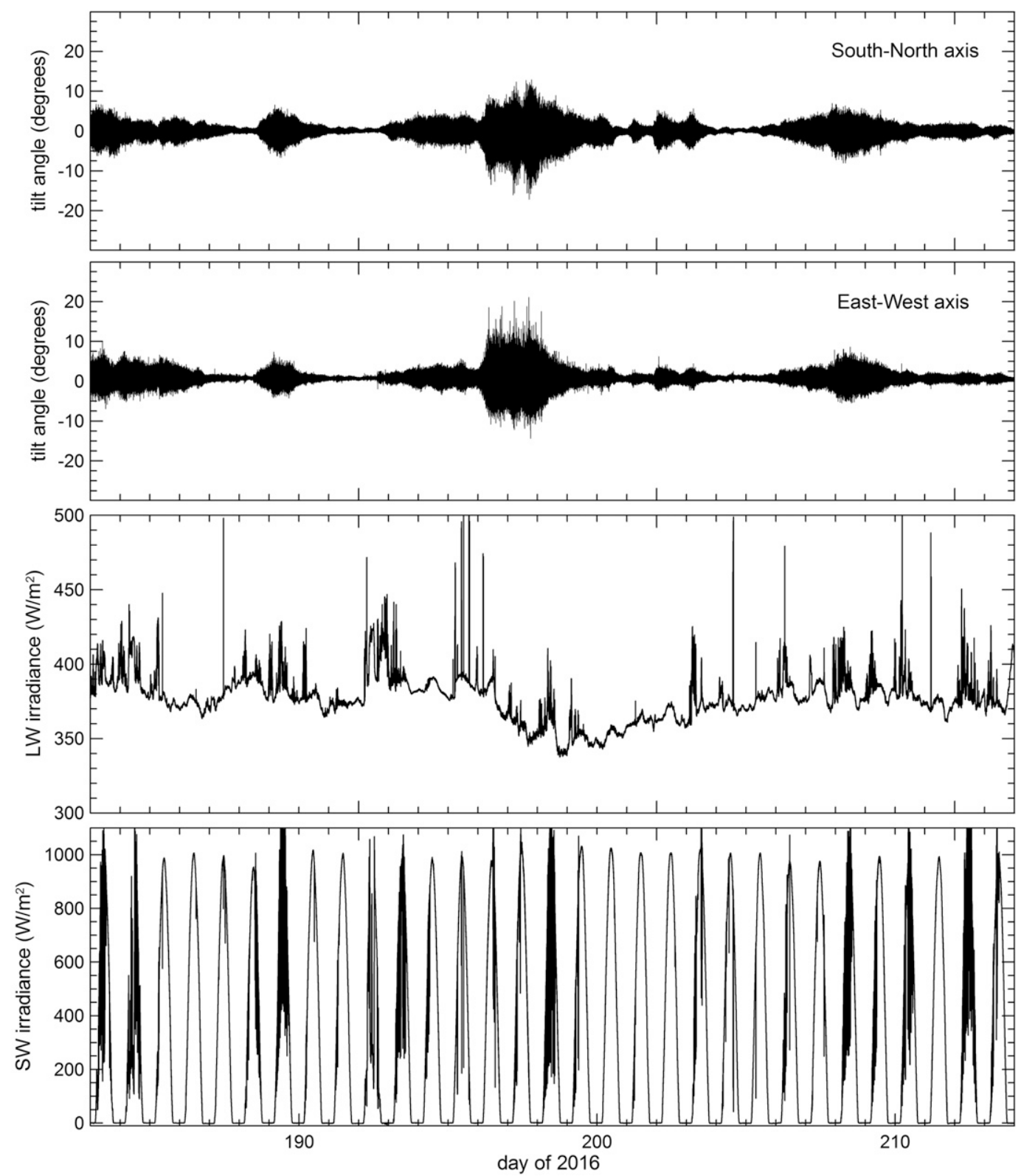

FIG. 4. As in Fig. 3, but for July 2016. Note that the vertical axis of SW and LW irradiance has been changed with respect to Fig. 3.

north-south axis, and $-0.27^{\circ}$ along the west-east axis). In the period 1-16 January 2016, $90 \%$ of the data are within $\pm 1.7^{\circ}$ along the west-east axis and within $\pm 1.8^{\circ}$ along the north-south axis.

Figure 6 shows the distribution of the radiometer tilt angles recorded in July 2016. Because of the better weather conditions, the distribution appears narrower than in January. The mean position for the east-west axis in July is at a tilt angle of $0.78^{\circ}$, and it is $0.08^{\circ}$ along the north-south axis. In July $90 \%$ of the data are composed between $\pm 1.0^{\circ}$ of the mean tilt angle along the west-east axis and between $\pm 1.3^{\circ}$ of the mean tilt angle along the north-south axis.

The inclinometer data show that oscillations are somewhat larger along the north-south axis than westeast. The distributions of tilt angles are not fully symmetrical around the mean angle. These effects are attributed to the role of prevailing wind and ocean current at Lampedusa. Prevailing and stronger winds are from the northern and northwestern sectors, thus possibly inducing a larger buoy oscillation along these directions. 


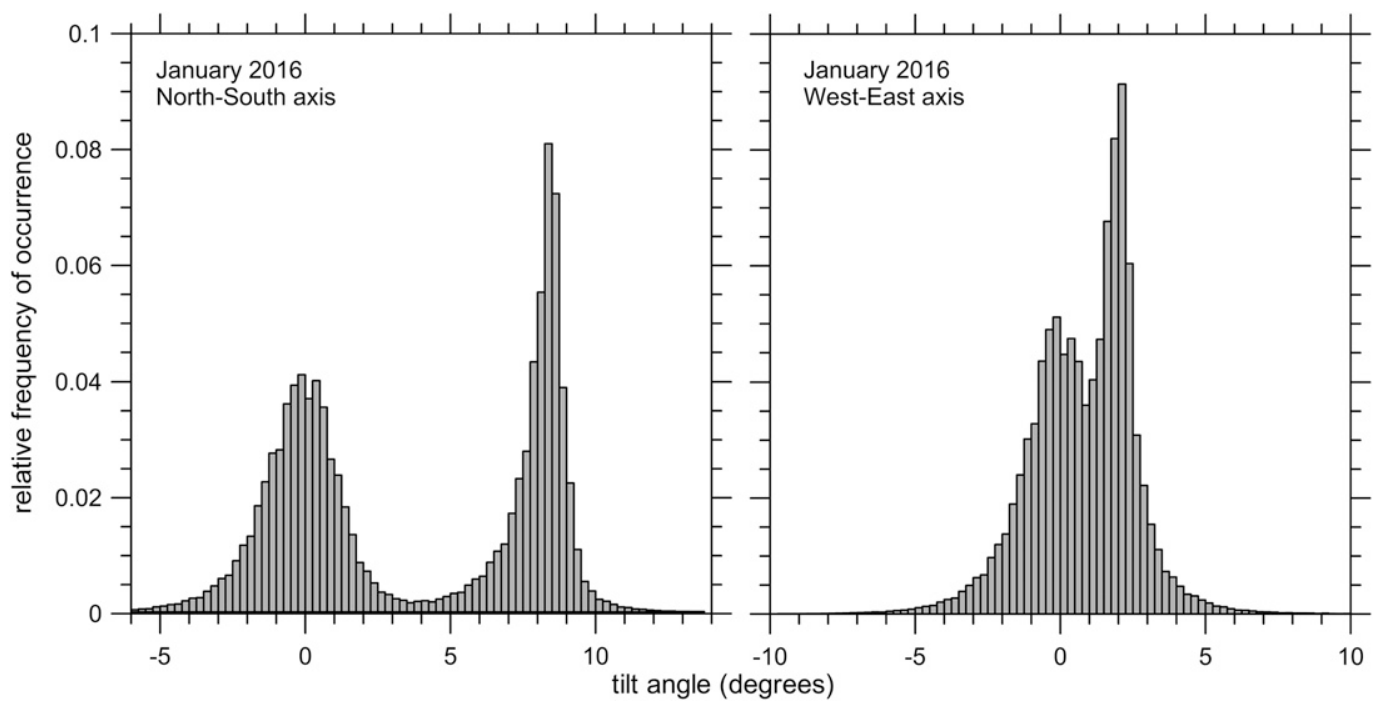

FIG. 5. Frequency of occurrence of the radiometer tilt angles along the approximate (left) north-south and (right) west-east axes. The mode centered at about $8^{\circ}$ in the left panel and the one centered around $2^{\circ}$ in the right panel are relative to the period after the $16-17$ Jan storm.

\section{b. Daily and hourly average SW and LW irradiance}

Hourly and daily (24h) averages of SW and LW irradiance, and of the tilt angles, were calculated from the measurements at $\mathrm{OO}$ and at AO. Figure 7 shows the evolution of the corresponding daily SW and LW irradiances throughout 2016. The shaded portion of the graphs corresponds to the period when the radiometer plate was tilted after the storm.

A good correspondence between the two datasets is present, including during most of the cloudy periods. This good correspondence supports the assumption that local orographic effects are very small at AO.
Systematic differences appear small, and somewhat larger for LW than for SW irradiances.

The time series of the differences between SW and LW daily averages at $\mathrm{OO}$ and $\mathrm{AO}$, and daily average radiometer tilt angles at OO are shown in Fig. 8. Days with moderate (daily precipitation $>1 \mathrm{~mm}$ ) and heavy $(>10 \mathrm{~mm})$ precipitation are also shown, together with days on which radiometer domes on the buoy were cleaned.

Precipitation may induce the cleaning or may lead to deposition of particles on the domes, mainly when occurring from dust laden clouds. Intense precipitation is

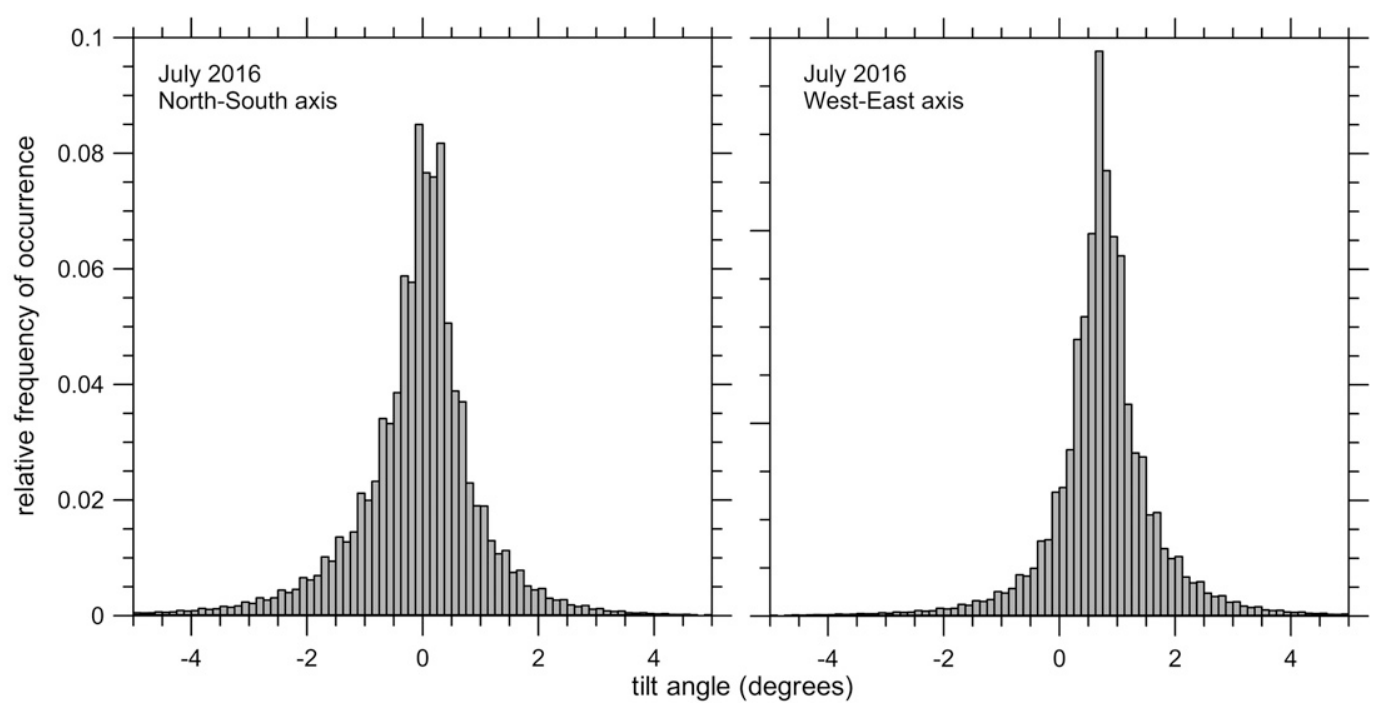

FIG. 6. As in Fig. 5, but for July 2016. Note that the horizontal axis has a different scale. 


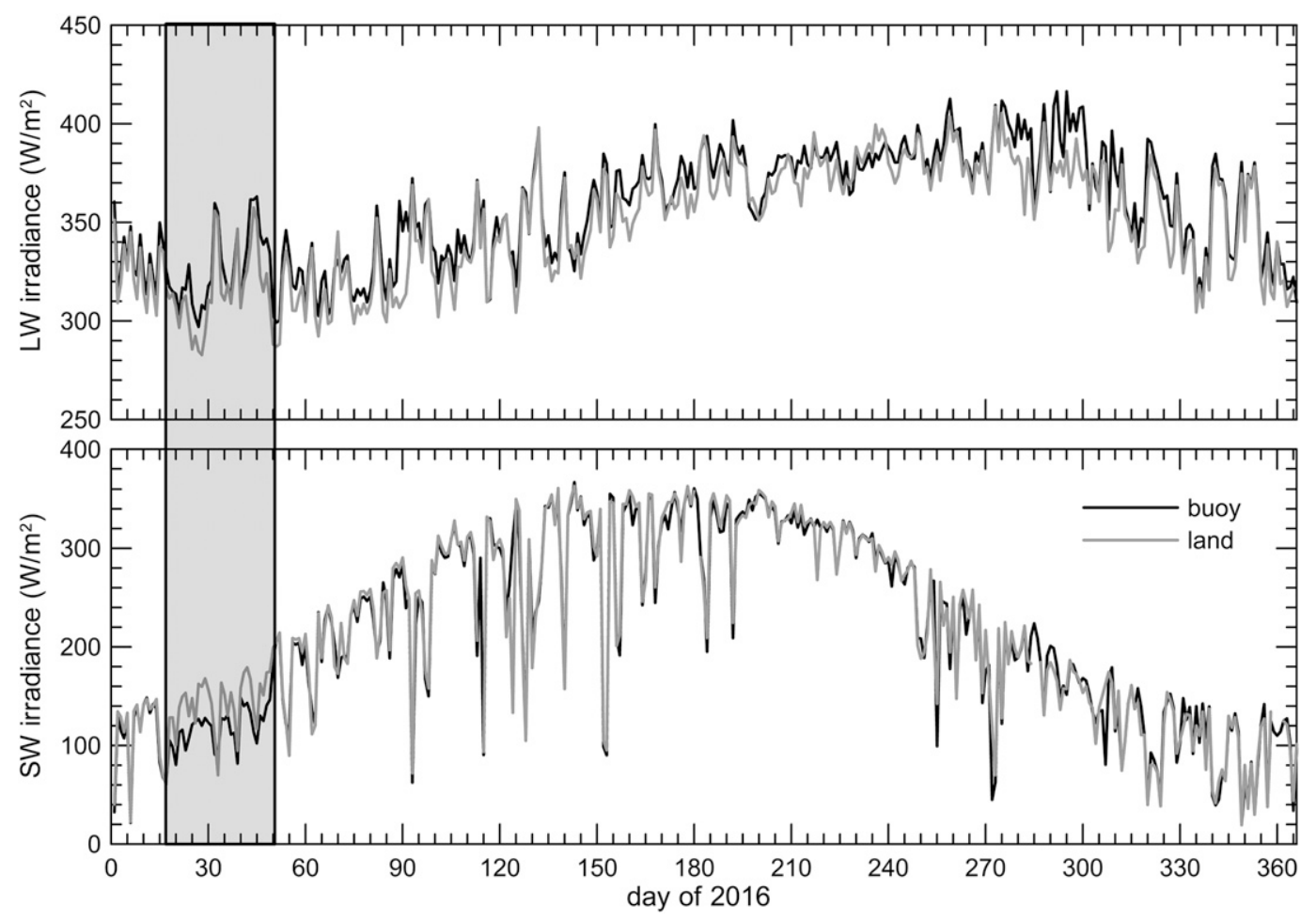

FIG. 7. Time series of (top) LW and (bottom) SW irradiances measured at OO and at AO. The shaded area corresponds to the period during which the radiometer plate was tilted after the storm.

probably more likely to help cleaning the domes. Figure 8 does not show a clear correspondence between $\mathrm{OO}-\mathrm{AO}$ differences and precipitation, possibly because of the variable effect of precipitation on the dome cleaning, or spatial inhomogeneity of rain processes. Conversely, intense precipitation events and manual dome cleaning seem to produce a reduction of the LW irradiance difference, and SW differences close to zero.

The radiometer attitude change occurred on 17 January evidently affected the SW irradiance, while the impact is difficult to detect for the LW irradiance. The radiometer attitude was adjusted on day 50 (19 February). On day 265 (21 September) the radiometer attitude along the westeast axis was improved while an offset in the north-south direction was introduced. Although this change may have produced an effect on the OO-AO differences, it is not clearly identifiable in Fig. 8.

Figure 9 shows the scatterplot between daily average SW and LW irradiances at OO and AO. Data from the period 16 January-19 February 2016 were excluded. Least squares fitting lines are drawn. The correlation coefficient is high in both cases. The mean bias (MB) has been calculated as the mean difference between measurements at $\mathrm{OO}$ and $\mathrm{AO}$ and is reported in Table 2. The difference between SW irradiance data at AO and $\mathrm{OO}$ is very small, with measurements at AO slightly larger than at OO. LW irradiance is conversely larger at $\mathrm{OO}$ than at $\mathrm{AO}$, with a $\mathrm{MB}$ of about $7.4 \mathrm{Wm}^{-2}$. The root-mean-square deviation (RMSD) is about $11 \mathrm{~W} \mathrm{~m}^{-2}$ for both components.

Values of MB and RMSD were also calculated in different time intervals, up to 21 September, from 21 September to 31 December and from 17 January to 18 February. The results of the calculations are also reported in Table 2. The SW irradiance OO-AO differences are generally negative, except after 21 September. A somewhat larger OO-AO LW irradiance bias is found between 17 January and 18 February and after 21 September. The increase of the SW irradiance on the buoy after 21 September is consistent with the negative tilt along the north-south axis, which corresponds with the radiometer slightly inclined toward the sun, producing a small positive bias. Conversely, a large decrease of SW irradiance is found in the period with the large positive tilt along the north-south axis. It is interesting to note that the OO-AO difference in LW irradiance increases for both negative and positive tilt values. This is probably due to the fact that a larger tilt, independently of the axis, leads to increase the fraction of sea surface and to decrease the fraction of sky falling within the pyrgeometer field of view. In many cases this induces an enhancement of the measured LW 

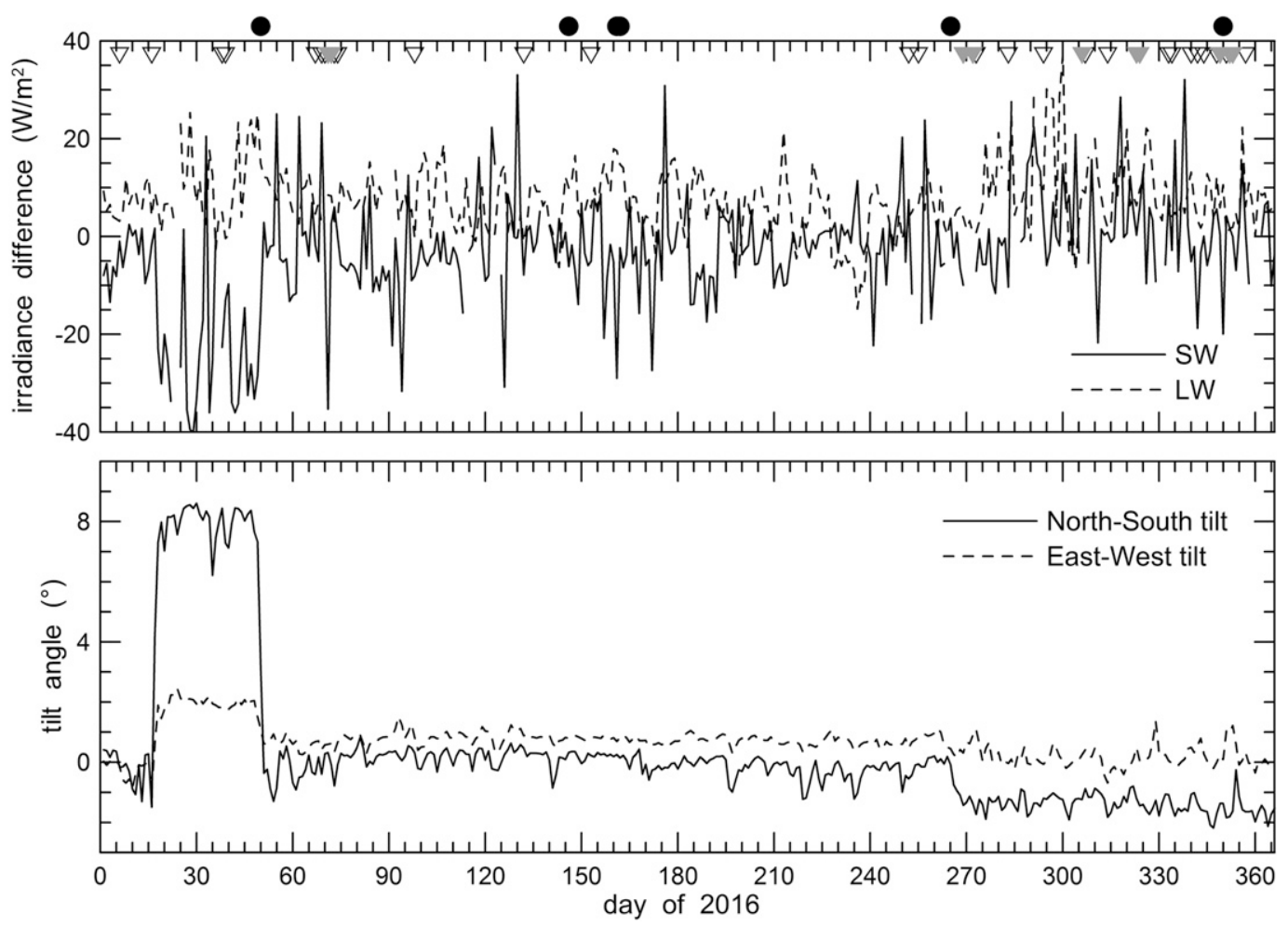

FIG. 8. (top) Time series of the differences between SW and LW daily averages at OO and AO, and (bottom) daily average tilt angles of the radiometers at OO. Open triangles close to the top axis correspond to days with precipitation of greater than $1 \mathrm{~mm}$; gray solid triangles correspond to days with precipitation of more than $10 \mathrm{~mm}$. Full circles above the top axis mark the days on which radiometers at $\mathrm{OO}$ were cleaned.

irradiance, and of its variability. For instance, the RMSD of the LW irradiance is larger during periods with the buoy radiometer mean tilt angle different from zero. Dome cleaning may, however, have had an effect, and it is difficult to totally attribute these differences to the change of tilt angle.

The OO-AO differences were also calculated from hourly averages. Fast cloud variability is expected to
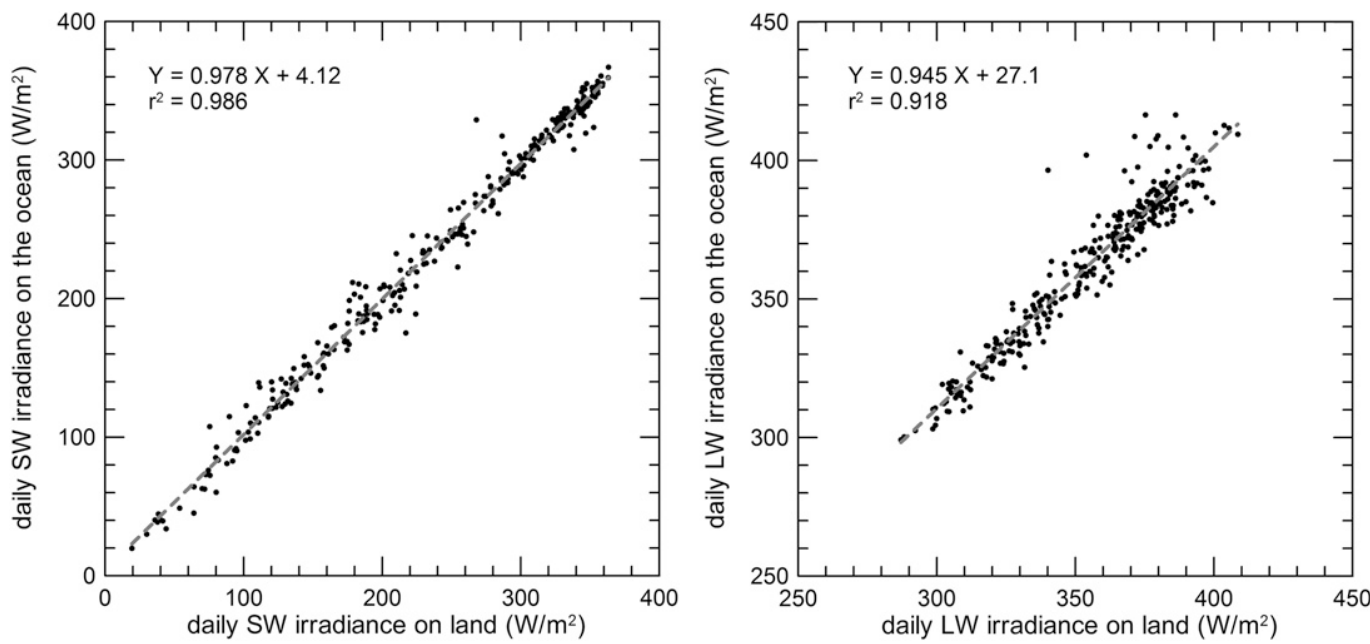

FIG. 9. Scatterplots between daily average (left) SW and (right) LW radiation measured at AO over land and at OO over the ocean, throughout year 2016. Data from 16 Jan and 19 Feb 2016, have been excluded. The linear least squares fit is shown for both components. The best fit and correlation coefficient are also displayed in each panel. 
TABLE 2. Mean bias and root-mean-square differences between SW and LW daily averages $\left(\mathrm{W} \mathrm{m}^{-2}\right)$ over different time intervals.

\begin{tabular}{lrccc}
\hline \hline Day no. period & SW MB & SW RMSD & LW MB & LW RMSD \\
\hline 1-16 and 50-366 & -1.2 & 10.6 & 7.4 & 10.8 \\
1-16 and 50-264 & -2.2 & 10.5 & 6.2 & 8.5 \\
17-49 & -25.5 & 29.3 & 10.0 & 12.7 \\
265-366 & +1.3 & 11.0 & 10.3 & 14.6 \\
\hline
\end{tabular}

produce larger effects on the hourly than on the daily averages. Similarly to the analysis of the daily averages, the mean bias between $\mathrm{OO}$ and $\mathrm{AO}$ was calculated over different time intervals in order to assess if the occurred attitude changes have affected observations at OO. Moreover, OO-AO differences were calculated also only over daytime for the SW component, and only for nighttime for the LW component. The summary of the results is reported in Table 3. The daytime SW data are selected by using only hourly values of $>30 \mathrm{~W} \mathrm{~m}^{-2}$. $\mathrm{LW}$ hourly data between 2100 and 0300 UTC are selected for the nighttime.

As expected, the MBs of the daytime SW hourly averages are larger than for daily averages, which are calculated over $24 \mathrm{~h}$ and include nighttime data. Similarly, the RMSD is larger for the daytime SW data than for the 24-h datasets. This is also expected since the RMSD of nighttime data is extremely small. The daytime SW mean bias has a significant increase, by more than $9 \mathrm{~W} \mathrm{~m}^{-2}$, after 21 September, and reaches about $+5 \mathrm{~W} \mathrm{~m}^{-2}$. All the SW biases are, however, $<1 \%$ with respect to the corresponding average SW irradiance, except for the daytime SW for the 265-366 period (1.6\%).

As suggested by Philipona et al. (2001), comparison of collocated pyrgeometers is favored in nighttime due to the absence of solar radiation, which may produce a differential heating of the dome, and may in part reach the detector due to solar radiation leakage of the filter. For this reason, the hourly LW irradiance measurements were also compared using only nighttime data. The MB values calculated throughout the whole day and in nighttime are similar, while RMSD is smaller for nighttime. The absence of ventilators on the buoy is expected to produce a larger bias in nighttime, when water condensation on the dome may occur more easily without ventilation. The behavior of RMSD seems to suggest much more stable conditions, and possibly, a reduced cloud variability, during nighttime.

The values of MB and RMSD were calculated over cloud-free periods to assess the role of clouds in the calculated differences between OO and AO. Daytime cloud-free hourly average data at $\mathrm{AO}$ were selected based on the cloud-screening algorithm described by Meloni et al. (2007). The algorithm, similar to that proposed by Long and Ackerman (2000), uses various thresholds on the absolute value of the global and diffuse solar irradiances, and on their time variability, and allows the identification of cloud-free conditions (cloud cover $<2$ oktas, and no clouds between the sun and the observer) also when high dust loads are present in the atmosphere (Meloni et al. 2007). The cloud-screening method can be applied to observations made at AO; thus, to remove the possible influence from small-scale clouds at OO, SW data whose hourly standard deviation $>15 \%$ of the hourly irradiance, and LW data whose hourly standard deviation $>2 \%$ of the hourly irradiance at $\mathrm{OO}$, have been discarded. The $\mathrm{MB}$ and RMSD were calculated over the identified daytime cloud-free periods, and the derived values are reported in Table 3. MB and RMSD were also calculated for the all-sky conditions daytime LW data (data between 0700 and 1400 UTC were selected).

The values of LW irradiance MB for daytime cloudfree conditions are similar to those obtained in all-sky conditions. The corresponding RMSD is similar to that found for nighttime LW data, except during the last months of the year, when the largest impact from clouds is expected.

The clouds impact in a larger way on the SW irradiance. The SW irradiance mean bias shows a limited change, except for the period 21 September-31 December, when

TABLE 3. Mean bias and root-mean-square deviation between hourly average SW and LW irradiances at OO and AO. Statistical parameters are calculated over different time intervals, over the $24 \mathrm{~h}$, and only for daytime or nighttime.

\begin{tabular}{|c|c|c|c|c|c|c|}
\hline \multirow{2}{*}{ Day no. interval: } & \multicolumn{2}{|c|}{$1-16$ and $50-366$} & \multicolumn{2}{|c|}{$1-16$ and $50-264$} & \multicolumn{2}{|c|}{$265-366$} \\
\hline & $\mathrm{MB}$ & RMSD & MB & RMSD & MB & RMSD \\
\hline Daytime SW & -1.8 & 57.5 & -4.2 & 54.7 & +5.1 & 66.2 \\
\hline SW & -1.0 & 39.9 & -2.1 & 39.2 & +0.8 & 39.6 \\
\hline Cloud-free daytime SW & +1.4 & 20.5 & -0.2 & 19.3 & +14.0 & 28.3 \\
\hline Nighttime LW & +7.2 & 8.6 & +6.2 & 7.2 & +9.4 & 20.5 \\
\hline Daytime LW & +8.4 & 10.3 & +6.9 & 8.2 & +11.7 & 27.9 \\
\hline LW & +7.7 & 15.8 & +6.3 & 12.5 & +10.4 & 22.7 \\
\hline Cloud-free daytime LW & +6.2 & 8.5 & +6.2 & 8.6 & +6.6 & 7.4 \\
\hline
\end{tabular}


it becomes significantly larger in cloud-free than in allsky conditions. The direct component of solar radiation is a larger fraction of global irradiance in cloud-free conditions, and the associated cosine response errors are expected to play a larger role. A significant reduction of RMSD for cloud-free conditions is found. This reduction is between $57 \%$ and $64 \%$ with respect to that found in daytime all-sky conditions. Thus, more of half of the variability between SW measurements at $\mathrm{AO}$ and OO may be ascribed to clouds. The 5th and 95th percentile of the relative differences between SW irradiance measurements at $\mathrm{OO}$ and $\mathrm{AO}$ for cloud-free daytime conditions are $-5 \%$ and $+5.3 \%$, respectively. This is in agreement with the differences found among collocated well calibrated pyranometers during an extended comparison lasting for 1 year (Habte et al. 2016).

As discussed above, the observed biases may be due to different possible causes. Cloud-free data collected on the buoy have been analyzed more in detail with the aim of separating the various possible contributions to the observed differences.

\section{c. Acceptable deviation from the horizontal position}

A simple criterion has been adopted to identify quasi horizontal irradiance measurements on the buoy. The criterion is based on the definition of a maximum acceptable uncertainty on the direct SW component due to the radiometer tilt, and on a simplified description of the downwelling irradiance. The maximum acceptable uncertainty is assumed to be $\pm 3 \mathrm{~W} \mathrm{~m}^{-2}$. The direct irradiance on the horizontal plane $I_{d}$ may be expressed as

$$
I_{d}=I_{o} \cos \theta \exp (-\tau / \cos \theta),
$$

where $I_{o}$ is the solar extraterrestrial irradiance, $\theta$ is the solar zenith angle, and $\tau$ is a total atmospheric pseudooptical depth (applicable to the whole solar spectral range). The change in $I_{d}, \Delta I_{d}$, associated with a change in solar zenith angle $\Delta \theta$ is

$$
\Delta I_{d}=I_{o} \exp (-\tau / \cos \theta) \sin \theta[1+\tau / \cos \theta] \Delta \theta,
$$

where $\Delta \theta$ is the deviation of the instrument tilt angle in the plane containing the radiometer, the vertical, and the sun.

If we assume $\Delta I_{d}=3 \mathrm{~W} \mathrm{~m}^{-2}$, the corresponding acceptable variation of solar zenith angle $\Delta \theta_{L}$ depends on $\theta$ and is given by

$$
\Delta \theta_{L}=3 /\left[I_{o} \exp (-\tau / \cos \theta) \sin \theta(1+\tau / \cos \theta)\right] .
$$

Figure 10 shows the behavior of $\Delta \theta_{L}$ versus solar zenith angle.

The instantaneous value of $\Delta \theta$ corresponding to the individual measurements on the buoy was calculated

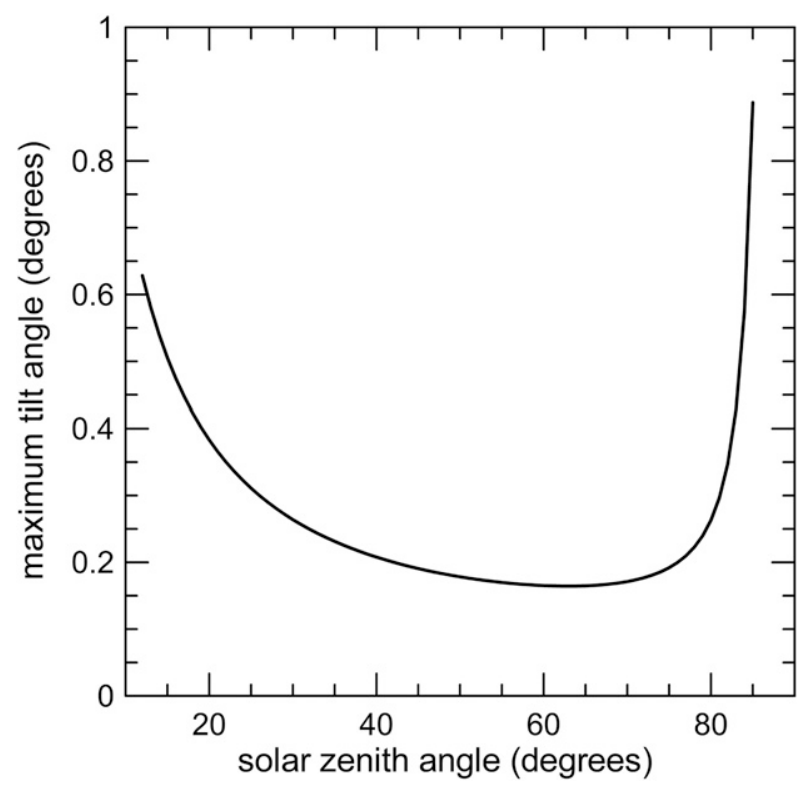

FIG. 10. Behavior of the maximum acceptable sensor tilt angle in the plane containing the vertical, the radiometer, and the sun, to have a variation of direct $\mathrm{SW}$ irradiance of less than $\pm 3 \mathrm{~W} \mathrm{~m}^{-2}$.

from the two axes' attitudes as in Boers et al. (1998), assuming that the buoy is not rotating. We have selected all cases with the sum of the two tilt angles $<\Delta \theta_{L}$ and compared the simultaneous measurements made at $\mathrm{AO}$ and at OO. This condition is more stringent than necessary; however, since we have no detailed information on the buoy rotation and the condition applies only to the direct component, we have preferred to make a conservative selection.

\section{d. Comparison of selected instantaneous clear-sky data}

Data belonging to the selected quasi-horizontal irradiance dataset were further classified, and a subset including measurements made during the $48 \mathrm{~h}$ following the cleaning of the domes on the buoy, and in cloud-free conditions was created. This subset thus includes data from several days in February, May, and June 2016. Cloud-free measurements were selected by visual inspection of the data obtained at $\mathrm{AO}$ and $\mathrm{OO}$, and using sky imager pictures acquired every minute at AO.

Figure 11 shows the instantaneous SW irradiance measurements made at $\mathrm{OO}$ versus those at $\mathrm{AO}$, for quasi-horizontal sensors, clean domes, and cloud-free conditions. The number of selected data is relatively small (about 100 data pairs). The linear least squares fit between buoy and land data is also shown in Fig. 11, together with correlation, MB, and RMSD. The mean bias is about $-2 \mathrm{~W} \mathrm{~m}^{-2}$ ( $\mathrm{SW}$ irradiance at $\mathrm{OO}$ lower than at AO). The reader is reminded that the data were 


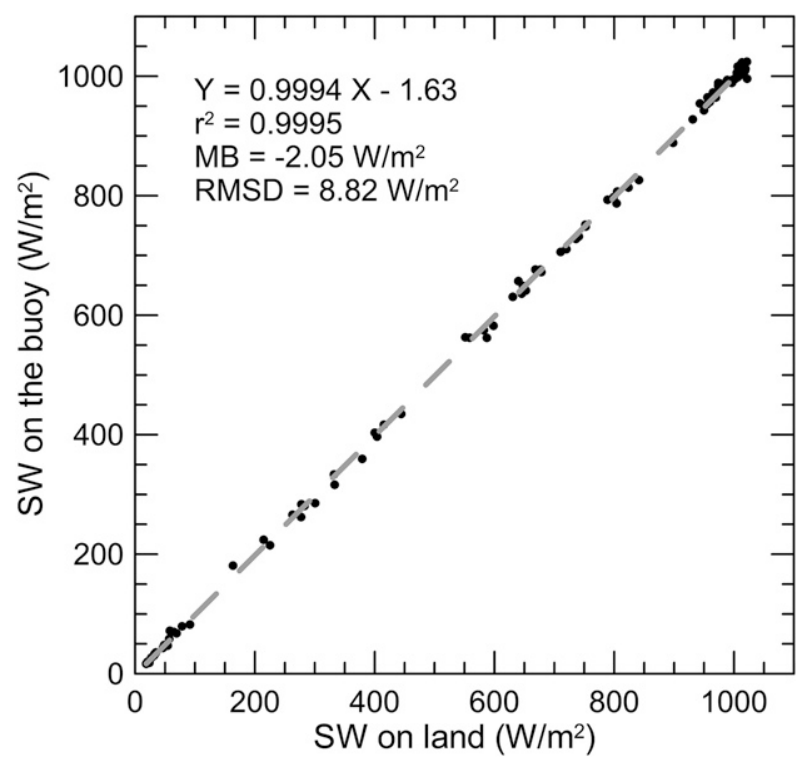

FIG. 11. SW irradiance measured at $\mathrm{OO}$ vs simultaneous instantaneous observations at $\mathrm{AO}$, for quasi-horizontal radiometers, clean domes, and cloud-free conditions (see text).

selected based on a $\pm 3 \mathrm{~W} \mathrm{~m}^{-2}$ acceptable uncertainty on the direct irradiance. Thus, the estimated bias is within the assumed limits for compatible measurements.

A similar analysis has been carried out for the LW irradiance. In this case, a weaker selection on the radiometer attitude was applied, due to the longer instrumental response time and lower expected dependency on the angle. For LW irradiance, all cases with both tilt angles smaller than $\Delta \theta_{L}$ have been selected. The LW dataset also includes nighttime data. Figure 12 shows the scatterplot of LW irradiance measurements made at $\mathrm{OO}$ and $\mathrm{AO}$ for clean dome, quasi horizontal data, and cloud-free conditions. The figure comprises several days in February, May, and June.

The correlation coefficient between the selected LW measurements at $\mathrm{OO}$ and $\mathrm{AO}$ (Fig. 12) is smaller than for SW, also a result of the smaller range of values attained by the LW irradiance. The mean bias is about $6 \mathrm{~W} \mathrm{~m}^{-2}$ (larger irradiance at $\mathrm{OO}$ than at $\mathrm{AO}$ ), and the RMSD is $6.7 \mathrm{~W} \mathrm{~m}^{-2}$. This RMSD is similar to that found in previous direct comparisons (Burns et al. 2000; Cronin et al. 2006).

Biases found for instantaneous data with quasihorizontal radiometers, clean domes, and cloud-free conditions are very close to those found for the daily averages throughout 2016. This seems to suggest that dome cleaning and radiometer attitude, as far as they are close to the horizontal position, have a limited effect on the SW and LW irradiances for the occurring conditions. Moreover, contrary to what was found in other small

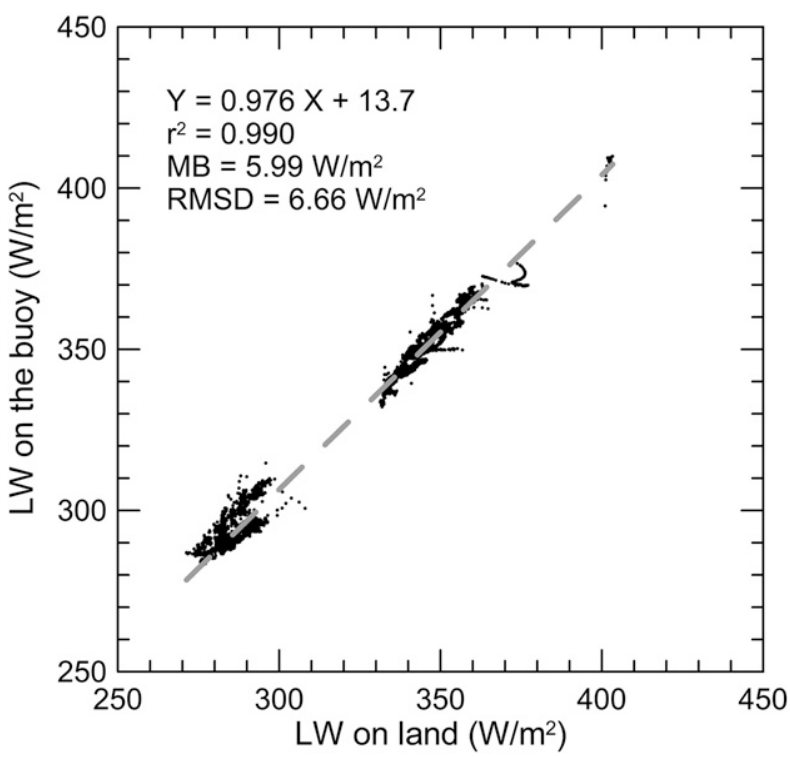

FIG. 12. As in Fig. 11, but for LW irradiance.

islands (Gautier 1988; Bishop et al. 1997), orographically induced effects on cloud properties may be considered to be negligible at Lampedusa. Thus, we may assume that the observed $\mathrm{OO}-\mathrm{AO}$ differences are primarily due to altitude and albedo.

\section{e. Dependence on tilt angles}

The dependence linking the SW irradiance and the radiometer tilt angle was investigated by using hourly mean data for January and February 2016. Within this time frame the radiometer attitude underwent significant changes, due to the bending of the radiometer supporting arm between 17 January and 19 February.

The solar zenith angle relative to the radiometer absorbing surface was calculated as in Boers et al. (1998) from the solar ephemeris and the two measured tilt angles under the assumption that the north-south axis is always pointing north (i.e., no rotation of the buoy). Differences between hourly data at $\mathrm{OO}$ and $\mathrm{AO}$ display a relatively large scatter (see section $3 b$ ). Data satisfying the following criteria were selected: hourly standard deviation at the buoy smaller than $10 \%$ of the value measured at $\mathrm{AO}$, hourly SW irradiance at $\mathrm{AO}>$ $100 \mathrm{~W} \mathrm{~m}^{-2}$, and hourly standard deviation of the tilt angle along the north-south direction $<0.25^{\circ}$. This selection allows us to identify relatively cloud-free data and to avoid solar zenith angles larger than $80^{\circ}$ possibly influenced by large cosine response errors, and highly variable radiometer attitudes. The percent difference between the SW irradiances measured at $\mathrm{OO}$ and at $\mathrm{AO}$ is plotted versus $\Delta \theta$ in Fig. 13. Four data points, clearly related to differences in cloud distributions at the two 


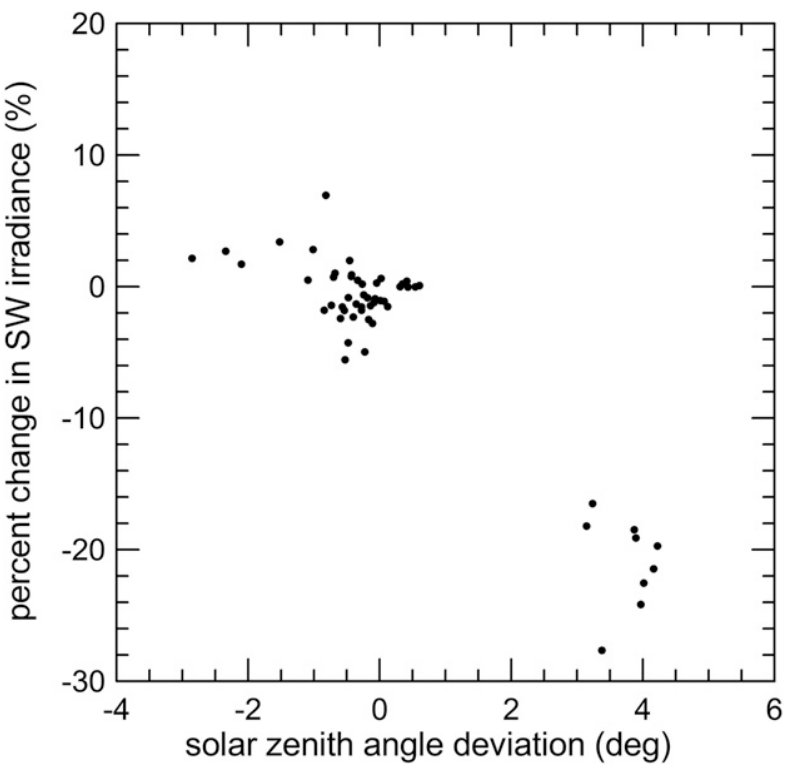

FIG. 13. Percent difference between hourly mean values of SW measurements at $\mathrm{OO}$ and $\mathrm{AO}$ for different values of the solar zenith angle deviation. Only data with $\mathrm{SW}$ irradiance $>100 \mathrm{~W} \mathrm{~m}^{-2}$ and small hourly variability of the irradiance and of the tilt angle have been selected (see text).

sites, were removed from the graph. The percent difference shows an evident dependency on $\Delta \theta$, with a decreasing measured SW for increasing solar zenith angle with respect to the radiometer. No conclusion can be drawn on the dependency for negative values of $\Delta \theta$. The deviation from the measured and the horizontal irradiance is estimated to be about $10 \%$ for $2^{\circ}$ and about $20 \%$ for $4^{\circ}$ variation with respect to the solar zenith angle.

Waliser et al. (1999) estimated a $2 \%-3 \%$ change in SW irradiance for a $1^{\circ}$ tilt toward the sun. This deviation seems to be smaller than found in the present analysis. Calculations by Katsaros and DeVault (1986) show that the relative error due to the pyranometer's tilt depends on the solar zenith angle. Their calculations show that in clear-sky conditions the deviation may exceed $10 \%$ for a $6^{\circ}$ tilt at solar zenith angles $>55^{\circ}$. MacWhorter and Weller (1991) performed measurements on a rocking system and derived deviations exceeding $10 \%$ for $5^{\circ}$ tilts toward the sun at solar zenith angles $>60^{\circ}$. The deviation also depends, however, on the rocking amplitude and on the instrumental cosine response, and values larger than those reported by MacWhorter and Weller (1991) may occur.

The dependence of the deviation between hourly average measurements at $\mathrm{OO}$ and $\mathrm{AO}$ was also studied for the LW irradiance. No significant changes in the deviation versus the tilt angle were found. The relatively long instrumental time constant may also play a role.

\section{Model calculations}

The comparison between measurements at $\mathrm{OO}$ and AO show a difference of about $-2 \mathrm{~W} \mathrm{~m}^{-2}$ for the $\mathrm{SW}$ irradiances, and of about $+6 \mathrm{~W} \mathrm{~m}^{-2}$ for the $\mathrm{LW}$ irradiance. These differences are attributed to the different environmental conditions of the measurements. Altitude (for SW and LW) and albedo (for SW) are the main factors that may produce differences in the irradiances at the two sites. The effect of altitude is due to scattering, absorption, and emission by the atmospheric constituents comprised between the altitude of $\mathrm{OO}$ and $\mathrm{AO}$, and the related differences in column amounts. Water vapor is expected to play an important role in the LW spectral range. Albedo changes primarily affect the upwelling SW irradiance; the downwelling irradiance is consequently influenced through downward scattering of upwelling radiation by atmospheric constituents. Radiative transfer simulations were carried out to verify if the observed differences are consistent with the expected albedo and altitude effects.

The MODTRAN, version 5.3, model has been used in the simulations (Berk et al. 2006). The model spectral resolution is $1 \mathrm{~cm}^{-1}$. The DISORT (Stamnes et al. 1988) multiple scattering method with eight streams with the fast and accurate correlated- $k$ option was used for the simulations in the IR spectral region. No aerosol were included in the model.

The following parameters were changed in the simulations: sensor altitude, surface albedo, solar zenith angle, vertical water vapor and temperature profiles. Calculations were made with sensor altitude of 7 and $50 \mathrm{~m}$, with ocean surface at $0 \mathrm{~m}$ and land surface at $45 \mathrm{~m}$.

Two different values of the SW surface albedo have been used. The ocean albedo from Jin et al. (2011), calculated for a wind speed of $6 \mathrm{~m} \mathrm{~s}^{-1}$, has been used to simulate the downwelling SW irradiance at OO. A mixed albedo, corresponding to $72 \%$ of ocean and $28 \%$ of barren/desert (Di Biagio et al. 2009) was used for the simulation at AO. The IR emissivity of the ocean surface was taken from Masuda et al. (1988). Calculations in the SW spectral range were made at the mean sunEarth distance and at solar zenith angles of $10^{\circ}, 25^{\circ}, 45^{\circ}$, $65^{\circ}, 75^{\circ}$, and $85^{\circ}$.

Two different atmospheric (i.e., pressure, temperature, and humidity) vertical profiles were used in the simulations. The profiles are derived from radiosonde measurements made at AO on 22 June 2013 (Meloni et al. 2018), as representative of the summer conditions, and on 28 February 2014, for winter conditions. The total column water vapor was $2.65 \mathrm{~cm}$ on 22 June 2013 and $1.14 \mathrm{~cm}$ on 28 February 2014. The column water vapor above $50 \mathrm{~m}$ altitude was $2.56 \mathrm{~cm}$ on 22 June 2013 
TABLE 4. Mean difference and root-mean-square deviation between SW and LW downwelling irradiance at $\mathrm{OO}$ and $\mathrm{AO}$ as resulting from measurements (data) and simulations with a radiative transfer model with summer and winter meteorological profiles.

\begin{tabular}{lcc}
\hline & $\mathrm{MD}\left(\mathrm{W} \mathrm{m}^{-2}\right)$ & $\mathrm{RMSD}\left(\mathrm{W} \mathrm{m}^{-2}\right)$ \\
\hline SW data & -2.05 & 8.82 \\
SW model, summer & -2.70 & 3.41 \\
SW model, winter & -3.04 & 3.54 \\
LW data & +5.99 & 6.66 \\
LW model, summer & +5.71 & - \\
LW model, winter & +8.39 & - \\
\hline
\end{tabular}

and $1.09 \mathrm{~cm}$ on 28 February 2014. The relative humidity at the surface was $80 \%$ on 22 June and $60 \%$ on 28 February.

Mean differences (MDs) between SW and LW measured irradiances at $\mathrm{OO}$ and at $\mathrm{AO}$ (the values from Fig. 11 and Fig. 12), and between modeled SW and LW irradiances at $7 \mathrm{~m}$ over the sea and at $50 \mathrm{~m}$ over land for the two selected atmospheric profiles are reported in Table 4. MD and RMSD among the model results at the two altitudes were calculated taking into account the 6 considered values of solar zenith angle used in the simulations.

The mean differences obtained from the model simulations are very close to those derived from the comparison of the instantaneous observations. However, the SW differences increase for decreasing solar zenith angle and, consequently, MD depends on the values of irradiance over which the mean is calculated. Moreover, they depend on the characteristics of the atmospheric profile, column water vapor amount, and aerosol properties. The results of Table 4 must thus be taken with caution. However, they suggest that the observed differences may be explained by the site characteristics. Radiative transfer calculations made varying altitude and surface albedo show that about $70 \%$ of the difference in the SW irradiances is due to albedo, and the remaining $30 \%$ to altitude. The difference between the $\mathrm{LW}$ irradiance at $\mathrm{OO}$ and $\mathrm{AO}$ is due to the combined effect of the additional water vapor in the lowest atmospheric layer, and its temperature.

\section{Conclusions}

Land and ocean radiation measurements at a limited distance $(15 \mathrm{~km})$ have been used to assess the quality of irradiance measurements made on the Lampedusa Oceanographic Observatory. Irradiances and radiometer attitudes have been acquired at $1 \mathrm{~Hz}$ on the buoy. The role of the radiometer domes cleaning and of the radiometer attitude are considered in the analysis. A radiative transfer model has been used to identify the origin of the differences between $\mathrm{OO}$ and $\mathrm{AO}$.
The main findings of this study may be summarized as follows:

- The mean bias and RMSD between daily SW irradiances measured at $\mathrm{OO}$ and $\mathrm{AO}$ during periods with radiometers mean position close to the horizontal are about -2.2 and $+10.5 \mathrm{Wm}^{-2}$, respectively. The mean bias and RMSD between daily LW irradiances are +6.2 and $8.5 \mathrm{~W} \mathrm{~m}^{-2}$, respectively. Small changes $\left(<2^{\circ}\right)$ of the radiometer mean tilt angle produce a $<1 \%$ change $(<2 \%$ when considering only daytime data) in daily SW irradiance at OO, and a small increase of the OO-AO LW irradiance difference.

- The comparison of hourly data produces similar biases and larger RMSD. On the basis of hourly averages, comparisons were made for daytime only and nighttime only data. The mean bias between $\mathrm{OO}$ and $\mathrm{AO} \mathrm{SW}$ irradiance daytime observations is about $-4 \mathrm{~W} \mathrm{~m}^{-2}$ when the mean attitude of the OO pyranometer is close to horizontal and becomes $+5 \mathrm{~W} \mathrm{~m}^{-2}$ in late September, November, and December, when the radiometers were tilted toward south by about $1.5^{\circ}$.

- Clouds appear to contribute significantly to the RMSD of SW irradiance measurements at $\mathrm{OO}$ and AO. The RMSD of SW irradiances in all-sky conditions in daytime is more than 2 times that in cloud-free conditions. Ninety percent of the SW irradiance differences for cloud-free conditions are between $-5 \%$ and $+5 \%$.

- The comparison between selected instantaneous measurements with horizontal radiometers, cloud-free conditions, and clean domes produces similar biases $\left(-2.1 \mathrm{~W} \mathrm{~m}^{-2}\right.$ for SW and $+6.0 \mathrm{~W} \mathrm{~m}^{-2}$ for LW irradiances) and smaller RMSDs $\left(8.8 \mathrm{~W} \mathrm{~m}^{-2}\right.$ for $\mathrm{SW}$ and $6.7 \mathrm{~W} \mathrm{~m}^{-2}$ for $\mathrm{LW}$ irradiances) with respect to the daily averages for all conditions. The similar values of the bias suggests that the influence of averaging tilt angle changes associated with the buoy rocking motion is small, as is the effect of dome cleaning at Lampedusa.

- By selecting data during a period when the radiometers were off from the horizontal, the role of mean tilt changes on the hourly average SW irradiance was investigated. Data show that a mean tilt of $4^{\circ}$ with respect to the solar zenith angle produces a $20 \%$ change in the measured SW irradiance; the effect of the radiometer tilt angle is small on the measured LW irradiances.

- Radiative transfer model simulations were used to assess the origin of the mean difference between SW and LW irradiances at $\mathrm{OO}$ and $\mathrm{AO}$. The observed 
differences are attributed to the effect of altitude (for the $\mathrm{LW}$, with the additional emission from the lowest atmospheric layers) and of albedo (for the SW).

This analysis suggests that measurements of SW and LW irradiances may be obtained in the Mediterranean Sea with an accuracy similar to that obtainable from ground-based observations. Follow-up analyses are being dedicated to investigate the surface energy budget in the Mediterranean and to validate satellite estimates of surface irradiance.

The representativeness of ground-based measurements on the island of Lampedusa with respect to openocean conditions is also assessed in this study, and associated biases are identified. This analysis opens the possibility of using the long-term radiation record at AO as a proxy for open-ocean observations.

Acknowledgments. The buoy at Lampedusa was developed within the RITMARE Flagship Project, supported by the Italian Ministry for University and Research. Measurements at $\mathrm{OO}$ and AO were supported by the same ministry through the RITMARE and NextData Projects. The left part of Fig. 2 is image ISS024-E-10246, provided through the courtesy of the Earth Science and Remote Sensing Unit at NASA Johnson Space Center (and has been downloaded from http://eol.jsc.nasa.gov).

\section{REFERENCES}

Berk, A., and Coauthors, 2006: MODTRAN5: 2006 update. Proc. SPIE, 6233, 62331F, https://doi.org/10.1117/12.665077.

Bishop, J. K. B., W. B. Rossow, and E. G. Dutton, 1997: Surface solar irradiance from the International Satellite Cloud Climatology Project 1983-1991. J. Geophys. Res., 102, 6883-6910, https://doi.org/10.1029/96JD03865.

Boers, R., P. B. Krummel, and R. M. Mitchell, 1998: Correction of aircraft pyranometer measurements for diffuse radiance and alignment errors. J. Geophys. Res., 103, 16 753-16 758, https:// doi.org/10.1029/98JD01431.

Bréon, F.-M., R. F. Frouin, and C. Gautier, 1991: Downwelling longwave irradiance at the ocean surface: An assessment of in situ measurements and parameterizations. J. Appl. Meteor., 30, 17-31, https://doi.org/10.1175/1520-0450(1991)030<0017: DLIATO $>2.0 . \mathrm{CO} ; 2$.

Burns, S. P., and Coauthors, 2000: Comparisons of aircraft, ship, and buoy radiation and SST measurements from TOGA COARE. J. Geophys. Res., 105, 15 627-15 652, https:// doi.org/10.1029/2000JD900090.

Canepa, E., S. Pensieri, R. Bozzano, M. Faimali, P. Traverso, and L. Cavaleri, 2015: The ODAS Italia 1 buoy: More than forty years of activity in the Ligurian Sea. Prog. Oceanogr., 135, 4863, https://doi.org/10.1016/j.pocean.2015.04.005.

Casasanta, G., A. di Sarra, D. Meloni, F. Monteleone, G. Pace, S. Piacentino, and D. Sferlazzo, 2011: Large aerosol effects on ozone photolysis in the Mediterranean. Atmos. Environ., 45, 3937-3943, https://doi.org/10.1016/j.atmosenv.2011.04.065.
Ciardini, V., and Coauthors, 2016: Global and Mediterranean climate change: A short summary. Ann. Ist. Super. Sanita, 52, 325-337, https://doi.org/10.4415/ANN_16_03_04.

Cronin, M. F., C. W. Fairall, and M. J. McPhaden, 2006: An assessment of buoy-derived and numerical weather prediction surface heat fluxes in the tropical Pacific. J. Geophys. Res., 111, C06038, https://doi.org/10.1029/2005JC003324.

Di Biagio, C., A. di Sarra, D. Meloni, F. Monteleone, S. Piacentino, and D. Sferlazzo, 2009: Measurements of Mediterranean aerosol radiative forcing and influence of the single scattering albedo. J. Geophys. Res., 114, D06211, https://doi.org/10.1029/ 2008JD011037.

di Sarra, A., G. Pace, D. Meloni, L. De Silvestri, S. Piacentino, and F. Monteleone, 2008: Surface shortwave radiative forcing of different aerosol types in the central Mediterranean. Geophys. Res. Lett., 35, L02714, https://doi.org/10.1029/2007GL032395.

- C. Di Biagio, D. Meloni, F. Monteleone, G. Pace, S. Pugnaghi, and D. Sferlazzo, 2011: Shortwave and longwave radiative effects of the intense Saharan dust event of 25-26 March, 2010, at Lampedusa (Mediterranean Sea). J. Geophys. Res., 116, D23209, https://doi.org/10.1029/ 2011JD016238.

Dubois, C., and Coauthors, 2012: Future projections of the surface heat and water budgets of the Mediterranean Sea in an ensemble of coupled atmosphere-ocean regional climate models. Climate Dyn., 39, 1859-1884, https://doi.org/10.1007/ s00382-011-1261-4.

Foltz, G. R., A. T. Evan, H. P. Freitag, S. Brown, and M. J. McPhaden, 2013: Dust accumulation biases in PIRATA shortwave radiation records. J. Atmos. Oceanic Technol., 30, 1414-1432, https://doi.org/10.1175/JTECH-D-12-00169.1.

Gautier, C., 1988: Surface solar irradiance in the tropical Pacific during Tropic Heat: Comparison between in situ measurements and satellite estimates. J. Climate, 1, 600-608, https://doi.org/ 10.1175/1520-0442(1988)001<0600:SSIITC > 2.0.CO;2.

Ghate, V. P., B. A. Albrecht, C. W. Fairall, and R. A. Weller, 2009: Climatology of surface meteorology, surface fluxes, cloud fraction, and radiative forcing over the southeast Pacific from buoy observations. J. Climate, 22, 5527-5540, https://doi.org/ 10.1175/2009JCLI2961.1.

Gilman, C., and C. Garrett, 1994: Heat flux parameterizations for the Mediterranean Sea: The role of atmospheric aerosols and constraints from the water budget. J. Geophys. Res., 99, 51195134, https://doi.org/10.1029/93JC03069.

Habte, A., M. Sengupta, A. Andreas, S. Wilcox, and T. Stoffel, 2016: Intercomparison of 51 radiometers for determining global horizontal irradiance and direct normal irradiance measurements. Sol. Energy, 133, 372-393, https://doi.org/ 10.1016/j.solener.2016.03.065.

Jin, Z., Y. Qiao, Y. Wang, Y. Fang, and W. Yi, 2011: A new parameterization of spectral and broadband ocean surface albedo. Opt. Express, 19, 26429-26443, https://doi.org/ 10.1364/OE.19.026429.

Katsaros, K. B., and J. E. DeVault, 1986: On irradiance measurement errors at sea due to tilt of pyranometers. J. Atmos. Oceanic Technol., 3, 740-745, https://doi.org/10.1175/15200426(1986)003<0740:OIMEAS > 2.0.CO;2.

Long, C. N., and T. P. Ackerman, 2000: Identification of clear skies from broadband pyranometer measurements and calculation of downwelling, shortwave cloud effects. J. Geophys. Res., 105, 152 609-152 626, https://doi.org/10.1029/2000JD900077.

_, A. Bucholtz, H. Jonsson, B. Schmid, A. Vogelmann, and J. Wood, 2010: A method of correcting for tilt from horizontal 
in downwelling shortwave irradiance measurements on moving platforms. Open Atmos. Sci. J., 4, 78-87, https://doi.org/10.2174/ 1874282301004010078.

MacWhorter, M. A., and R. A. Weller, 1991: Error in measurements of incoming shortwave radiation made from ships and buoys. J. Atmos. Oceanic Technol., 8, 108-117, https://doi.org/ 10.1175/1520-0426(1991)008<0108:EIMOIS > 2.0.CO;2.

Mailler, S., and Coauthors, 2016: On the radiative impact of aerosols on photolysis rates: Comparison of simulations and observations in the Lampedusa Island during the CharMEx/ADRIMED campaign. Atmos. Chem. Phys., 16, 1219-1244, https://doi.org/10.5194/acp-16-1219-2016.

Masuda, K., T. Takashima, and Y. Takayama, 1988: Emissivity of pure and sea waters for the model sea surface in the infrared window regions. Remote Sens. Environ., 24, 313-329, https:// doi.org/10.1016/0034-4257(88)90032-6.

Mateos, D., A. di Sarra, D. Meloni, C. Di Biagio, and D. M. Sferlazzo, 2011: Experimental determination of cloud influence on the spectral UV radiation and implications for biological effects. J. Atmos. Sol. Terr. Phys., 73, 1739-1746, https://doi.org/10.1016/j.jastp.2011.04.003.

Matsoukas, C., A. C. Banks, N. Hatzianastassiou, K. G. Pavlakis, D. Hatzidimitriou, E. Drakakis, P. W. Stackhouse, and I. Vardavas, 2005: Seasonal heat budget of the Mediterranean Sea. J. Geophys. Res., 110, C12008, https://doi.org/10.1029/ 2004JC002566.

Medovaya, M., D. E. Waliser, R. A. Weller, and M. J. McPhaden, 2002: Assessing ocean buoy shortwave observations using clear-sky model calculations. J. Geophys. Res., 107, 3014, https://doi.org/10.1029/2000JC000558.

Meloni, D., A. di Sarra, J. R. Herman, F. Monteleone, and S. Piacentino, 2005: Comparison of ground-based and TOMS erythemal UV doses at the island of Lampedusa in the period 1998-2003: Role of tropospheric aerosols. J. Geophys. Res., 110, D01202, https://doi.org/10.1029/2004JD005283.

_ — - G. Biavati, J. J. DeLuisi, F. Monteleone, G. Pace, S. Piacentino, and D. Sferlazzo, 2007: Seasonal behavior of Saharan dust events at the Mediterranean island of Lampedusa in the period 1999-2005. Atmos. Environ., 41, 3041-3056, https:// doi.org/10.1016/j.atmosenv.2006.12.001.

— C. Di Biagio, A. di Sarra, F. Monteleone, G. Pace, and D. M. Sferlazzo, 2012: Accounting for the solar radiation influence on downward longwave irradiance measurements by pyrgeometers. J. Atmos. Oceanic Technol., 29, 1629-1643, https://doi.org/10.1175/JTECH-D-11-00216.1.

- , and Coauthors, 2015: Altitude-resolved shortwave and longwave radiative effects of desert dust in the Mediterranean during the GAMARF campaign: Indications of a net daily cooling in the dust layer. J. Geophys. Res. Atmos., 120, 33863407, https://doi.org/10.1002/2014JD022312.

_ effects of Saharan dust: A radiative transfer modelling study based on vertically resolved measurements at Lampedusa. Atmos. Chem. Phys., 18, 4377-4401, https://doi.org/10.5194/ acp-18-4377-2018.

Michalsky, J. J., L. C. Harrison, and W. E. Berkheiser III, 1995: Cosine response characteristics of some radiometric and photometric sensors. Sol. Energy, 54, 397-402, https://doi.org/ 10.1016/0038-092X(95)00017-L.

Nabat, P., and Coauthors, 2015: Dust aerosol radiative effects during summer 2012 simulated with a coupled regional aerosol-atmosphere-ocean model over the Mediterranean.
Atmos. Chem. Phys., 15, 3303-3326, https://doi.org/10.5194/ acp-15-3303-2015.

Pascal, R. W., and S. A. Josey, 2000: Accurate radiometric measurement of the atmospheric longwave flux at the sea surface. J. Atmos. Oceanic Technol., 17, 1271-1282, https://doi.org/ 10.1175/1520-0426(2000)017<1271:ARMOTA > 2.0.CO;2.

Pettenuzzo, D., W. G. Large, and N. Pinardi, 2010: On the corrections of ERA-40 surface flux products consistent with the Mediterranean heat and water budgets and the connection between basin surface total heat flux and NAO. J. Geophys. Res., 115, C06022, https://doi.org/10.1029/2009JC005631.

Philipona, R., C. Fröhlich, and C. Betz, 1995: Characterization of pyrgeometers and the accuracy of atmospheric longwave radiation measurements. Appl. Opt., 34, 1598-1605, https:// doi.org/10.1364/AO.34.001598.

— uncertainty: Pyrgeometers compared to an absolute skyscanning radiometer, atmospheric emitted radiance interferometer, and radiative transfer model calculations. J. Geophys. Res., 106, 28 129-28141, https://doi.org/10.1029/ 2000JD000196.

Pinker, R. T., H. Wang, and S. A. Grodsky, 2009: How good are ocean buoy observations of radiative fluxes? Geophys. Res. Lett., 36, L10811, https://doi.org/10.1029/2009GL037840.

Ravaioli, M., and Coauthors, 2016: The RITMARE Italian FixedPoint Observatory Network (IFON) for marine environmental monitoring: A case study. J. Oper. Oceanogr., 9 (Suppl.), s202-s214, https://doi.org/10.1080/1755876X.2015.1114806.

Servain, J., A. J. Busalacchi, M. J. McPhaden, A. D. Moura, G. Reverdin, M. Vianna, and S. E. Zebiak, 1998: A Pilot Research Moored Array in the Tropical Atlantic (PIRATA). Bull. Amer. Meteor. Soc., 79, 2019-2031, https://doi.org/ 10.1175/1520-0477(1998)079<2019:APRMAI > 2.0.CO;2.

Stamnes, K., S.-C. Tsay, W. Wiscombe, and K. Jayaweera, 1988: Numerically stable algorithm for discrete-ordinate-method radiative transfer in multiple scattering and emitting layered media. Appl. Opt., 27, 2502-2509, https://doi.org/10.1364/ AO.27.002502.

Tragou, E., and A. Lascaratos, 2003: Role of aerosols on the Mediterranean solar radiation. J. Geophys. Res., 108, 3025, https://doi.org/10.1029/2001JC001258.

Waliser, D. E., R. A. Weller, and R. D. Cess, 1999: Comparison between buoy-observed, satellite-derived, and modeled surface shortwave flux over the tropical North Atlantic during the Subduction Experiment. J. Geophys. Res., 104, 31 301-31 320, https://doi.org/10.1029/1999JD900946.

Weller, R. A., and S. P. Anderson, 1996: Surface meteorology and air-sea fluxes in the western equatorial Pacific warm pool during the TOGA Coupled Ocean-Atmosphere Response Experiment. J. Climate, 9, 1959-1990, https://doi.org/10.1175/ 1520-0442(1996)009<1959:SMAASF>2.0.CO;2.

_, S. P. Bigorre, J. Lord, J. D. Ware, and J. B. Edson, 2012: A surface mooring for air-sea interaction research in the Gulf Stream. Part I: Mooring design and instrumentation. J. Atmos. Oceanic Technol., 29, 1363-1376, https://doi.org/10.1175/ JTECH-D-12-00060.1.

WMO, 2014: Guide to meteorological instruments and methods of observation. WMO Rep. 8, 1128 pp.

Yamada, K., and T. Hayasaka, 2016: Evaluation of the accuracy of downward radiative flux observations at the sea surface. J. Oceanogr., 72, 553-565, https://doi.org/10.1007/s10872-0150345-x. 